\title{
EL DERECHO A LA PRUEBA EN COLOMBIA: ASPECTOS FAVORABLES Y CRÍTICOS DE LA REFORMA DEL Código general del proceso en el DERECHO SUSTANCIAL Y PROCESAL*
}

\author{
THE RIGHT TO EVIDENCE IN \\ COLOMBIA: FAVORABLE ASPECTS \\ AND CRITICS OF THE REFORM OF THE \\ GENERAL PROCEDURAL CODE IN THE \\ SUBSTANTIVE AND PROCEDURAL LAW
}

\author{
Diego Armando Yáñez-Meza** \\ Jeferson Arley Castellanos-Castellanos***
}

Fecha de recepción: 9 de noviembre de 2015

Fecha de aceptación: 1 de febrero de 2016

Disponible en línea: 31 de mayo de 2016

* El presente artículo de investigación hace parte del proyecto El derecho a la prueba en Colombia: aspectos favorables y críticos con la reforma del Código General del Proceso, desarrollado por el semillero de investigación en derecho administrativo Louis-Antoine Macarel como producto del grupo de investigación en derecho público, Universidad Libre Seccional Cúcuta, adscrito a la línea de investigación Conocimiento, innovación y desarrollo sostenible regional, sublínea Justicia, derecho procesal y sistema penal acusatorio. Los autores agradecen a los integrantes del semillero Paola Andrea Osorio-Vanegas, Paula Andrea Llanes-Méndez, Ana Milena Chaustre-González, Paola López-Guerrero, María Victoria Carvajalino-Clavijo, Paola Andrea Cárdenas-Andrade, Daniela Laguado-Salazar, Bayron Omar Albarracín-Monsalve y Sandra Milena Mendoza-Moreno. Así mismo, a los auxiliares de investigación Sandra Esthebaly López-Vergel, Luis José ManosalvaRamírez y Claudia Liliana Figueroa-Mendoza.

** Abogado, Universidad Libre Seccional Cúcuta. Especialista en derecho público, Universidad Externado de Colombia. Magíster en derecho administrativo (investigativo), Universidad Externado de Colombia. Magíster (C) en derecho procesal contemporáneo (investigativo), Universidad de Medellín. Autor de distintos artículos de investigación. Director grupo de investigación en derecho público y del semillero de investigación en derecho administrativo Louis-Antoine Macarel, Universidad Libre Seccional Cúcuta. Docente en pregrado en la cátedra derecho administrativo general y colombiano, y responsabilidad civil. Docente en posgrados. Contacto: diego.yanez@unilibrecucuta. edu.co; diegoymezabogado@gmail.com

*** Estudiante, quinto año de derecho, Universidad Libre Seccional Cúcuta. Monitor del semillero de investigación en derecho administrativo Louis-Antoine Macarel. Estudiante ganador del VIII Concurso de Técnicas de Juicio Oral, organizado por el Departamento de Justicia de Estados Unidos. Estudiante ganador del Concurso Internacional para Estudiantes Reformas procesales en Colombia y en el mundo, organizado por la Universidad de Medellín en el marco del VII Congreso Internacional de Derecho Procesal. Contacto: jeferson.castellanos@unilibrecucuta.edu.co; jefersoncastellanos228@gmail.com 


\section{Para citar este artículo / To cite this article}

Yáñez-Meza, Diego Armando \& Castellanos-Castellanos, Jeferson Arley, El derecho a la prueba en Colombia: aspectos favorables y críticos de la reforma del Código General del Proceso en el derecho sustancial y procesal, 132 Vniversitas, 561-610 (2016). http://dx.doi.org/10.11144/Javeriana.vj132.dpca

doi:10.11144/Javeriana.vj132.dpca

\section{RESUMEN}

Actualmente, uno de los mandatos estructurales para la tutela efectiva de los derechos es el derecho fundamental a la prueba, no solo por el novedoso fenómeno de constitucionalización del proceso, sino por casos concretos que han impulsado serias reformas. Con anterioridad al Código General del Proceso, el ciudadano que acudía a la administración de justicia veía definida la vigencia y eficacia de su pretensión o excepción por medio de tres hipótesis de la actividad probatoria: i) la habilidad o dirigida intención de su contraparte de aportar o no la prueba del hecho, que es otra manera de entender la noción clásica de carga de la prueba; ii) la búsqueda de la verdad por parte del juez, mediante sus poderes oficiosos; y iii) la sorpresa de una inversión de la carga de la prueba por el juez, de la cual la persona a quien se le asignaba la carga de probar se enteraba en la sentencia de segunda instancia, o en sede de casación o en la eventual revisión. En la actualidad, con el CGP y el Estatuto de Arbitraje Nacional e Internacional, se le aumentan los poderes de instrucción al juez, al permitírsele i) asignar la carga de probar a la parte de la relación procesal que se encuentra en mejor posición de hacerlo y ii) decretar medidas cautelares probatorias; esta nueva realidad implica redefinir y examinar lo que denominaremos los "insumos" a los cuales puede acudir el juez que pretenda hacer una protección efectiva del derecho a la prueba, en la etapa de proposición y requerimiento de la prueba. Como consecuencia, se plantea la disertación frente a la afectación del derecho sustancial de este derecho fundamental, de una parte, y en torno a los serios desafíos frente a la estructura y el trámite creado para la carga dinámica desde el CGP, abordados desde sus aspectos críticos en lo que se considera eminentemente procesal.

Palabras clave: Derecho a la prueba; etapa de proposición y requerimiento de la prueba; carga de la prueba; prueba de oficio; inversión de la carga de la prueba; carga dinámica de la prueba; medida cautelar probatoria

\section{ABSTRACT}

Currently one of the structural mandates for the effective protection of rights is the fundamental right to the evidence, not only because of the new phenomenon of constitutionalization process but by the experience of indi- 
vidual cases, which have driven it serious reforms. Before the General Code of Procedure its reality reveals a citizen who comes to the administration of justice and sees defined the validity and effectiveness of its claim or exception through three systems: $i)$ the ability or directed intention of his or her counterpart in providing or no evidence of the fact, which is another way to understand the classical notion of who has to show the evidence; ii) in the search for truth by the judge, through his functions; and iii) the surprise of looking for evidence, which the person is assigned to take the evidence get know in the judgment that he had to do it. Nowadays with the GCP and the Status of National and International Arbitration, the functions of the judge will increase, to be allowed to assign the burden of proving on the part of the procedural relationship which is in a better position to do so and enact measures evidentiary precautionary, which means to define and to study what we call the "input" or "bags" to which the judge can go intending to make an effective protection of the right to evidence the proposition stage and requirement of the test, which under this new legislation actually affects the substantive law of this fundamental right, on one hand, and the structure of this new institution towards some aspects that defined the GCP, which can be approached from its critical aspects in what is considered eminently procedural.

Keywords: Right to the evidence; to take the evidence; function evidence; shifting the burden of evidence; dynamic burden evidence; probation injunction

\section{SUMARIO}

INTRODUCCIÓN.- I. PRoblema JURÍDICO.- II. Hipótesis.- III. ESQUEMA DE RESOLUCión.- A. El derecho fundamental a la prueba en la jurisprudencia de la Corte Constitucional.- 1. La carga de la prueba o carga estática de la prueba.- a. Discusión y crítica sobre la carga de la prueba o carga estática de la prueba.- 2 . Inversión de la carga de la prueba.- a. Discusión y crítica sobre la inversión de la carga de la prueba.- 3. La prueba de oficio.- a. Discusión y crítica sobre la prueba de oficio.- 4. La carga dinámica de la prueba.- a. La carga dinámica de la prueba y su asimilación con el concepto de la inversión de la carga de la prueba: nuestro criterio de investigación que las diferencia.- b. La carga dinámica de la prueba como facultad: cuestión discutible a partir de una interpretación sistemática del CGP.- c. Discusión y crítica sobre la carga dinámica de la prueba.- $\mathrm{d}$. En relación con la exclusiva procedencia del recurso de reposición y la exclusión del recurso de apelación frente al auto que distribuye o niega la distribución de la carga de la prueba.- e. En relación con el momento procesal límite en el que el juez es competente para distribuir la carga de la prueba: esencia de la etapa de instrucción y juzgamiento.- $f$. En relación con la consecuencia jurídica frente al incumplimiento del deber asignado a la parte el distribuírsele la carga de la prueba.- 5. La medida cautelar probatoria.- a. Discusión y crítica sobre la medida cautelar probatoria.- CONCLUSIONES.- BIBLIOGRAFÍA. 


\section{INTRODUCCIÓN}

A partir del i) Código Civil (en adelante, CC)1, pasando por el ii) Código de Procedimiento Civil (en adelante, $\mathrm{CPC})^{2}$, iii) subreglas de la jurisprudencia constitucional, ejemplo, frente a sujetos que ostentan una especial protección constitucional - población desplazada, menores de edad, personas de la tercera edad y demás sujetos en circunstancias de debilidad manifiesta-, iv) subreglas de la jurisprudencia contencioso administrativa, ejemplo, en materia de responsabilidad del Estado por la actividad médico sanitaria, v) la Constitución Política de $1991^{3}$, vi) el Código General del Proceso (en adelante, CGP) ${ }^{4}$ y vii) el Estatuto de Arbitraje Nacional e Internacional ${ }^{5}$, se identifica actualmente el referente normativo que garantiza el derecho a la prueba en la etapa de proposición y requerimiento de la prueba en el proceso judicial en Colombia.

En materia de carga de la prueba y para todas las especialidades del derecho, es pacífico encontrar en la doctrina diversas discusiones ${ }^{6}$ sobre quién debe probar lo alegado en el proceso en relación con el trípode demandante-demandado-juez. Desde aquí se plantea la cuestión sobre la prueba de los hechos por estos sujetos mediante el contraste del anterior referente normativo, para tratar de establecer los aspectos favorables o críticos que la reforma del CGP introdujo sobre el derecho a la prueba en lo sustancial (etapa de proposición y requerimiento) y en lo procesal (estructura del proceso), para determinar su influencia en la tragedia de la persona que acude ante

1 Colombia, Ley 57 de 1887, por la cual se expide el Código Civil, CC. Disponible en: http:// www.secretariasenado.gov.co/senado/basedoc/codigo_civil.html

2 Colombia, Decreto 1400 de 1970, por el cual se expide el Código de Procedimiento Civil, CPC, 33.150 Diario Oficial, 21 de septiembre de 1970. Disponible en: http://www.alcaldiabogota. gov.co/sisjur/normas/Normal.jsp?i=6923

3 Colombia, Constitución Política, 7 de julio de 1991. Versión corregida, 116 Gaceta Constitucional, 20 de julio de 1991, disponible en: http://www.secretariasenado.gov.co/senado/basedoc/ constitucion_politica_1991.html

4 Colombia, Ley 1564 de 2012, por medio de la cual se expide el Código General del Proceso, CGP y se dictan otras disposiciones, 48.489 Diario Oficial, 12 de julio de 2012. Disponible en: http://www.secretariasenado.gov.co/senado/basedoc/ley_1564_2012.html

5 Colombia, Ley 1563 de 2012, por medio de la cual se expide el Estatuto de Arbitraje Nacional e Internacional y se dictan otras disposiciones, 48.489 Diario Oficial, 12 de julio de 2012. Disponible en: http://www.secretariasenado.gov.co/senado/basedoc/ley_1563_2012.html

6 A título de ejemplo se resalta la discusión teórica suscitada entre Jairo Parra-Quijano y Adolfo Alvarado-Velloso. Jairo Parra-Quijano, Racionalidad e ideología en las pruebas de oficio (1 ${ }^{\text {a }}$ ed., Editorial Temis S.A., Bogotá, 2004). Adolfo Alvarado-Velloso, Debido proceso versus pruebas de oficio (1 ${ }^{\mathrm{a}}$ ed., Editorial Temis S.A., Bogotá, 2004). 
el juez, en busca de la protección efectiva del derecho que considera afectado, de conformidad a su pretensión o su resistencia.

La prueba en el proceso judicial o administrativo es la piedra angular del iter mediante el cual se escruta en el pasado para conocer cómo ocurrieron los hechos y otorgar la protección efectiva al derecho o interés que se presenta. Esa naturaleza - construida a partir de la evolución, retroceso y confrontación del modelo anglosajón y continental europeo, desde la Edad Media hasta la posmodernidad y lo contemporáneo ${ }^{7}$ - presenta en la actualidad un punto de vital discusión. Ciertamente, entre las propiedades "puras" del modelo inquisitivo y dispositivo, lo que puede hacer el juez en el ejercicio de la jurisdicción se cuestiona, porque actúa más allá de lo que estos modelos le definen (activismo judicial) o porque simplemente parece inactivo frente a lo que ocurre en su expediente (garantismo).

Esta vacilante e interminable crítica a las fortalezas y funciones del juez, que se ve atacado con una u otra teoría, requiere una visión del sistema normativo aplicable en Colombia, a fin de determinar cuáles son los insumos reales con los que cuenta el juez para definir el debate probatorio que se le presenta, en relación con la llegada de la prueba al proceso. Con lo anterior, sin lugar a dudas, se debe tener en cuenta que en la totalidad de los casos judiciales el problema radica en que: i) el juez reconozca cuáles son sus armas, que se identifican en los poderes probatorios y deberes, y que ii) el juez esté consciente sobre qué puede hacer con esos insumos8.

Naturalmente, debe haber un presupuesto inamovible para dar respuesta a la cuestión: el Estado social de derecho, con su ideología estructural democrática, social y liberal, le impide al juez el papel de simple espectador, siendo claramente identificable y característico un papel interventor ${ }^{9}$ en el proceso.

7 Diana María Ramírez-Carvajal, La prueba en el proceso. Una aventura intelectual ( $1^{a}$ ed., Librería Jurídica Sánchez R. Ltda., Medellín, 2013).

8 Cuando se hace referencia en el presente artículo al termino insumos, se hace relación con los instrumentos jurídicos que tiene el juez para garantizar, en el proceso judicial, el derecho a la prueba y, en consecuencia, al debido proceso.

9 MirJan R. DamašKa, Las caras de la justicia y el poder del Estado (1 ${ }^{\mathrm{a}}$ ed., Editorial Jurídica de Chile, Santiago de Chile, 2000). Disponible en: https://books.google.com.co/ books?id=1A4MqsNMfMAC\&pg=PA1\&lpg=PA1\&dq=Las + caras + de + la + justicia\&source $=$

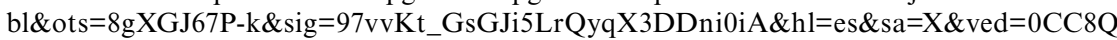
6AEwA2oVChMIw_qJmqTqyAIVyBceCh0xZQIh\#v=onepage\&q=Las $\% 20$ caras $\% 20 \mathrm{de} \% 20$ $1 \mathrm{a} \% 20 \mathrm{justicia} \& \mathrm{f}=\mathrm{f}$ 


\section{PROBlema JURÍDico}

Conforme a las variables definidas, la cuestión planteada aborda dos aspectos, uno eminentemente sustancial frente al derecho a la prueba, y otro marcadamente procesal frente a la forma como se concibió en la Ley el trámite de la carga dinámica de la prueba. En este sentido, se presenta el siguiente problema:

¿Cuáles son los insumos esenciales del derecho fundamental a la prueba en la etapa de proposición y requerimiento de la prueba, en virtud de la reforma definida desde el Código General del Proceso y los principales aspectos discutibles en cuanto a la configuración establecida para la distribución de la carga dinámica de la prueba, conforme a la estructura del proceso verbal?

\section{HIPóTESIS}

Del análisis completo y suficiente de los referentes normativos previos al CGP y su contraste, y en relación con el propósito definido para la investigación se puede afirmar lo siguiente:

1. En lo sustancial, en los casos concretos, el juez tiene cinco insumos para garantizarle al proceso el derecho a la prueba. En otros términos, el juez tiene cinco alternativas a las cuales acudir para encontrar el sustento de los hechos que se le presentan y sobre los cuales debe definir la pretensión de las partes o de los intervinientes en el proceso. Estos insumos son: a) la carga de la prueba, b) la inversión de la carga de la prueba, c) la prueba de oficio, d) la carga dinámica de la prueba y e) la medida cautelar probatoria.

2. En lo procesal, bajo lo establecido en el artículo 167 del CGP - carga dinámica de la prueba - se identifican los siguientes aspectos discutibles: i) la carga dinámica de la prueba como facultad, ii) la exclusiva procedencia del recurso de reposición frente al auto que distribuye la carga, iii) el momento procesal hasta el cual puede el juez distribuir la carga de la prueba en el proceso verbal, y iv) la inexistencia de consecuencia jurídica expresa frente a la parte a la cual se le asigna el deber de probar por el juez y que incumple ese mandato. 


\section{ESQUEMA DE RESOLUCIÓN}

Para la resolución del problema jurídico, 1) se hará referencia teórica del derecho a la prueba desde la jurisprudencia de la Corte Constitucional en casos concretos; posteriormente, 2) se desarrollarán los contenidos esenciales de lo que se ha denominado los "insumos" que garantizan el derecho a la prueba en el proceso; luego, 3) se enunciarán algunos criterios relevantes sobre el punto sustancial del derecho y en torno a su evolución o retroceso en la materia, en un ítem titulado discusión y finalmente, 4) se expondrá la problemática frente a los aspectos discutibles en cuanto a la solicitud, decreto y práctica de la carga dinámica de la prueba en el CGP.

\section{A. El derecho fundamental a la prueba en la jurisprudencia de la Corte Constitucional}

La doctrina internacional autorizada ${ }^{10}$ expresa que el "derecho a la prueba es un derecho de rango constitucional inmerso en la tutela efectiva y el debido proceso, que participa de la naturaleza compleja de estos, pues se implica con el derecho de defensa, derecho a ser oído, a contradecir y a la decisión conforme a derecho". Desde la jurisprudencia constitucional colombiana, se puede afirmar que este derecho ha sido moldeado por escasos desarrollos de la Corte Constitucional ${ }^{11}$, y desde una perspectiva muy ligada a casos propios

10 Rodrigo Rivera-Morales, Derecho constitucional de la prueba, en VIII Congreso Internacional de Derecho Procesal, 211-232 (1 $1^{a}$ ed., Universidad Libre Seccional Cúcuta, Cúcuta, 2012).

11 A continuación, se presentan las razones que en las decisiones existentes han desarrollado el derecho fundamental a la prueba en la jurisprudencia de la Corte Constitucional, al emplear el descriptor "derecho a la prueba" en el buscador de esa corporación. Debe aclararse que si bien es posible que en el defecto fáctico y el defecto procedimental como causales de procedibilidad de la acción de tutela contra sentencias, se analizan cuestiones probatorias, las únicas sentencias que sistemáticamente desarrollan postulados concretos frente al "derecho a la prueba" son exclusivamente las siguientes: En la Sentencia T-555-99, la Corte Constitucional señala al respecto: "El derecho a la prueba incluye no solamente la certidumbre de que, habiendo sido decretada, se practique y evalúe, sino la de que tenga incidencia lógica y jurídica, proporcional a su importancia dentro del conjunto probatorio, en la decisión que el juez adopte". Corte Constitucional, Sala Quinta de Revisión, Sentencia T-555-99, 2 de agosto de 1999, expediente T-197404, magistrado ponente José Gregorio Hernández-Galindo. Disponible en: http://www.corteconstitucional.gov.co/relatoria/1999/t-555-99.htm. De igual forma en la Sentencia T-589-99, indica: "De la misma manera, el derecho internacional consagra la protección al debido proceso, y, en particular, al derecho a la prueba. En este sentido, resulta relevante recordar que los más importantes tratados globales y hemisféricos sobre la materia incluyen entre las garantías mínimas del proceso, el derecho de la persona acusada a interrogar a los testigos llamados por los otros sujetos procesales y a lograr la comparecencia 
de otras personas que puedan declarar a su favor y ayudar a esclarecer los hechos. 7. La defensa del derecho a la prueba, como una de las dimensiones del derecho de defensa, llevó al legislador a consagrar, en el artículo 333 del Código de Procedimiento Penal, el imperativo de la investigación integral. Según el precitado artículo, el funcionario judicial tiene la obligación de investigar tanto lo favorable como lo desfavorable a los intereses del sindicado. Como lo ha señalado la jurisprudencia, el imperativo de la investigación integral se aplica en todas las etapas del proceso y no solo en la fase del juicio. A este respecto, la Corte ha indicado que el fiscal y no solo el juez, 'debe investigar tanto lo favorable como lo desfavorable al sindicado y, además, debe permitir la controversia probatoria y juzgar imparcialmente su valor de convicción'... 12. En el presente caso podría argumentarse que el derecho a la prueba, es decir, el derecho de defensa del acusado, debe ser reparado mediante la acción de tutela. A favor de este aserto, podría señalarse que, pese al evidente estado de indefensión en el que fue colocado el actor por parte de la funcionaria instructora, la apoderada de oficio no hizo uso de las oportunidades procesales que le brindó la etapa de juicio para reparar la lesión cometida. En efecto, como fue mencionado en los antecedentes, la defensora de oficio de Mauricio Camacho-Triana [el actor de este caso] dejó vencer los términos para recurrir la resolución de acusación, así como para solicitar pruebas y nulidades dentro del juicio (artículo 446 del CPP), sin haber realizado la más mínima gestión en defensa de su poderdante. En consecuencia, podría afirmarse que el mecanismo judicial alternativo actualmente existente, no es verdaderamente idóneo, en la medida en que la defensora del acusado dejó de interponer los recursos de ley contra la resolución de acusación y omitió solicitar, dentro del término establecido en el artículo 446 del CPP, las nulidades o pruebas conducentes. En estas condiciones, a favor de la procedencia de la acción de tutela, podría aplicarse la tesis de la Corte según la cual la negligencia del apoderado de oficio no puede operar en contra del sindicado cuando, de por medio, se verifica la vulneración flagrante de los derechos fundamentales de este". Corte Constitucional, Sala Tercera de Revisión, Sentencia T-589-99, 13 de agosto de 1999, expediente T-210000, magistrado ponente Eduardo Cifuentes-Muñoz. Disponible en: http://www.corteconstitucional.gov.co/relatoria/1999/t-589-99.htm. Colombia, Ley 906 de 2004, por la cual se expide el Código de Procedimiento Penal, CPP, 45.658 Diario Oficial, 1 de septiembre de 2004. Disponible en: http://www.secretariasenado.gov.co/senado/ basedoc/ley_0906_2004.html. Así mismo, en la Sentencia T-171-06, la Corte Constitucional destaca: "Es necesario indicar que el derecho a la prueba constituye uno de los principales ingredientes del debido proceso, así como del derecho al acceso a la administración de justicia y el más importante vehículo para alcanzar la verdad en una investigación judicial. Por tanto, las anomalías que desconozcan de manera grave e ilegítima este derecho, constituyen un defecto fáctico que, al vulnerar derechos fundamentales, pueden contrarrestarse a través de la acción de tutela... Los derechos de este sujeto procesal en sentido pleno, deben garantizársele en el proceso penal mediante el respeto de sus facultades y atribuciones en las diversas etapas del mismo, pues la estrategia procesal de las víctimas ya no se limita a un aspecto patrimonial sino que se constituye en la búsqueda de la verdad y la justicia, siendo imperativo concluir que una de sus principales herramientas la constituye el derecho a la prueba... En este orden de ideas, en caso de concluir que la acción es procedente, la Sala considera pertinente estudiar (i) los derechos de las víctimas, perjudicados y la parte civil, en el trámite de un proceso penal, así como (ii) las connotaciones del derecho a ser juzgado en un plazo razonable y sin dilaciones indebidas, para luego (iii) reiterar la doctrina de esta Corporación sobre las causales genéricas de procedibilidad de la acción de tutela contra providencias judiciales, específicamente frente a las condiciones inherentes al derecho a la prueba... 4.2.1. En primer lugar, vale la pena tener en cuenta la tutela T-504 de 1998, en donde se consideró que una de las manifestaciones más dañinas del debido proceso en los trámites judiciales, consiste es [sic] desconocer el derecho a la prueba de las partes. Al respecto, en esta sentencia se arguyó textualmente: ...4.2.6. Así las cosas, dada la importancia del derecho a la prueba, es necesario agregar que este tribunal ha definido las condiciones básicas a tener en cuenta para excluir o eliminar cualquiera de ellas del trámite de una actuación judicial. En efecto, en la sentencia SU-159 de 2002, el pleno de la Corte estudió las reglas de exclusión derivadas del último inciso del artículo 29 de la Constitución, a partir de un caso en el cual se invocaron 
al proceso penal, aunque sea indiscutible su extensión a cualquier otra especialidad del proceso judicial — procesal administrativo, civil, laboral, etc.- - dado el contenido constitucional que imprime la interpretación autorizada de la Corte Constitucional. De aquí por qué el estudio se limitará a este juez, principalmente.

En esta labor de construcción de los contenidos del derecho fundamental a la prueba, esta jurisprudencia la ha identificado como: a) la certidumbre frente al decreto, práctica, evaluación e incidencia lógica y jurídica proporcional a la importancia dentro del conjunto probatorio en la decisión del juez, b) el derecho a interrogar, c) el derecho a lograr la comparecencia de personas a fin de esclarecer los hechos, d) la controversia probatoria, e) el

la existencia de unos defectos fácticos y procedimentales presentes en una investigación penal, para lo cual indicó que las pruebas se pueden catalogar como inconstitucionales o ilícitas, según el estatuto normativo que tengan el poder de contrariar. En todo caso - se advirtió en aquella oportunidad - la eliminación o supresión de una prueba lleva inmersa la manifestación expresa y oportuna del funcionario competente, con el objetivo de garantizar el debido proceso de los sujetos procesales... 7.1. El derecho a la prueba obligaba en este caso particular a las autoridades judiciales a esperar su llegada del exterior a fin de valorarla, aunque el término de la instrucción estuviere vencido... 7.1.2. Ahora bien. Es claro que una de las condiciones para el debido ejercicio de los derechos dentro del proceso penal, es la obligación tanto de la 'parte civil' como del 'sindicado', entre otros, de respetar los términos procesales que definen el alcance y la magnitud temporal de las diferentes etapas, fases o períodos que componen un proceso judicial, pues al igual que el derecho a la prueba, el acatamiento diligente de los términos o el acceso a una investigación sin dilaciones injustificadas constituye ingrediente fundamental del debido proceso. Mandato constitucional que se extiende igualmente a las autoridades judiciales encargadas de resolver los asuntos judiciales quienes están obligadas a respetar los términos procesales... Sin embargo, es necesario aclarar que la protección del derecho a la prueba de las víctimas no puede ser desmedida. La Corte no puede permitir que con el objetivo de proteger este derecho se extienda indefinidamente el término para adelantar la investigación 1255 (542480). Por el contrario, debe quedar claro que (i) esto no permite o legitima la solicitud o el decreto de nuevas pruebas y (ii) que una vez satisfecho el derecho sustancial, consistente en allegar y valorar las pruebas decretadas por la Fiscalía, debe dársele trámite perentorio y urgente al proceso". Corte Constitucional, Sala Octava de Revisión, Sentencia T-171-06, 7 de marzo de 2006, expediente T-1226076, magistrada ponente Clara Inés Vargas-Hernández. Disponible en: http://www.corteconstitucional. gov.co/relatoria/2006/t-171-06.htm. Finalmente, la Corte en la Sentencia T-077-09 refiere la materia y aunque en la Sentencia T-171-06 se refiere que en la Sentencia T-504-98 se expresa la existencia o referencia del derecho a la prueba, hecha la revisión de la sentencia no se identifica la expresión, conforme al descriptor o criterio de selección que se ha enunciado. Corte Constitucional, Sala Primera de Revisión, Sentencia T-504-98, 10 de septiembre de 1998, expediente T-176879, magistrado ponente Alfredo Beltrán-Sierra. Disponible en: http:// www.corteconstitucional.gov.co/relatoria/1998/t-504-98.htm. Corte Constitucional, Sala Octava de Revisión, Sentencia T-171-06, 7 de marzo de 2006, expediente T-1226076, magistrada ponente Clara Inés Vargas-Hernández. Disponible en: http://www.corteconstitucional. gov.co/relatoria/2006/t-171-06.htm. Corte Constitucional, Sala Novena de Revisión, Sentencia T-077-09, 12 de febrero de 2009, expediente T-1842367, magistrada ponente Clara Inés Vargas-Hernández. Disponible en: http://corteconstitucional.gov.co/relatoria/2009/t-077-09. htm 
juzgar imparcialmente el valor de su convicción, f) el derecho de defensa, g) uno de los principales ingredientes del debido proceso y el acceso a la administración de justicia, h) el más importante vehículo para alcanzar la verdad en una investigación judicial, i) la búsqueda de la verdad y la justicia, y j) la exclusión de la prueba inconstitucional o ilícita.

Resulta importante en este punto una aclaración metodológica: esta gama de elementos variopintos del derecho a la prueba dentro del proceso, a pesar de la existencia de contadas decisiones de la Corte Constitucional que reseñan y configuran la expresión el "derecho a la prueba" en su texto ${ }^{12}$, seguramente se identifican en un gran número de decisiones en las que se examinó el defecto fáctico entre las causales específicas de procedibilidad de la acción de tutela contra providencias judiciales y, sin duda, esta denominación ha sido el fruto de cada una de ellas. Sin embargo, se aclara que no corresponde a esta investigación realizar una identificación y análisis sobre la causal específica de procedibilidad de la acción de tutela contra providencias judiciales en el defecto fáctico, por cuanto no es este el propósito de la investigación.

A partir de este contexto, se destacan dos consecuencias angulares del derecho: primera, la justicia constitucional ${ }^{13}$, teniendo como

12 Las sentencias referenciadas en las que la Corte Constitucional ha estudiado el "derecho a la prueba" son, se insiste, exclusivamente las siguientes: Corte Constitucional, Sala Plena, Auto A227-07, 29 de agosto de 2007, referencia: solicitud de nulidad de la Sentencia T-233 de 2007, proferida por la Sala Quinta de Revisión de Tutelas de la Corte Constitucional, magistrado ponente Marco Gerardo Monroy-Cabra. Expediente: T-1498919. Disponible en: http://www. corteconstitucional.gov.co/relatoria/autos/2007/a227-07.htm. Corte Constitucional, Sala Plena, Sentencia C-610-12, 1 de agosto de 2012, expediente D-8941, magistrado ponente Luis Ernesto Vargas-Silva. http://www.corteconstitucional.gov.co/relatoria/2012/c-610-12.htm. Corte Constitucional, Sala Quinta de Revisión, Sentencia T-555-99, 2 de agosto de 1999, expediente T-197404, magistrado ponente José Gregorio Hernández-Galindo. Disponible en: http://www.corteconstitucional.gov.co/relatoria/1999/t-555-99.htm. Corte Constitucional, Sala Tercera de Revisión, Sentencia T-589-99, 13 de agosto de 1999, expediente T-210000, magistrado ponente Eduardo Cifuentes-Muñoz. Disponible en: http://www.corteconstitucional. gov.co/relatoria/1999/t-589-99.htm. Corte Constitucional, Sala Séptima de Revisión, Sentencia T-1276-05, 6 de diciembre de 2005, expediente T-1166403, magistrado ponente Humberto Antonio Sierra-Porto. Disponible en: http://corteconstitucional.gov.co/relatoria/2005/t-1276-05. $\mathrm{htm}$. Corte Constitucional, Sala Octava de Revisión, Sentencia T-171-06, 7 de marzo de 2006, expediente T-1226076, magistrada ponente Clara Inés Vargas-Hernández. Disponible en: http://www.corteconstitucional.gov.co/relatoria/2006/t-171-06.htm. Corte Constitucional, Sala Novena de Revisión, Sentencia T-077-09, 12 de febrero de 2009, expediente T-1842367, magistrada ponente Clara Inés Vargas-Hernández. Disponible en: http://corteconstitucional. gov.co/relatoria/2009/t-077-09.htm

13 Corte Constitucional, Sala Octava de Revisión, Sentencia T-171-06, 7 de marzo de 2006, expediente T-1226076, magistrada ponente Clara Inés Vargas-Hernández. Disponible en: 
fuente la Constitución, señaló que el derecho a la prueba "lleva inmerso la capacidad y prerrogativa a: (i) la proposición o requerimiento de la prueba; (ii) el pronunciamiento sobre su admisibilidad; (iii) a la inclusión en el proceso y, finalmente, (iv) a la valoración o apreciación de las mismas conforme a las reglas de la sana crítica"14. Segunda, ha referido que el derecho a la prueba encuentra unos límites ya que "(i) no permite o legitima la solicitud o el decreto de nuevas pruebas y (ii) que una vez satisfecho el derecho sustancial, consistente en allegar y valorar las pruebas... debe dársele trámite perentorio y urgente al proceso" 15 .

http://www.corteconstitucional.gov.co/relatoria/2006/t-171-06.htm

14 Corte Constitucional, Sala Plena, Auto A227-07, 29 de agosto de 2007, referencia: solicitud de nulidad de la Sentencia T-233 de 2007, proferida por la Sala Quinta de Revisión de Tutelas de la Corte Constitucional, magistrado ponente Marco Gerardo Monroy-Cabra. Expediente: T-1498919. Disponible en: http://www.corteconstitucional.gov.co/relatoria/autos/2007/a227-07. htm. Corte Constitucional, Sala Plena, Sentencia C-610-12, 1 de agosto de 2012, expediente D-8941, magistrado ponente Luis Ernesto Vargas-Silva. http://www.corteconstitucional.gov. co/relatoria/2012/c-610-12.htm. Corte Constitucional, Sala Quinta de Revisión, Sentencia T-555-99, 2 de agosto de 1999, expediente T-197404, magistrado ponente José Gregorio Hernández-Galindo. Disponible en: http://www.corteconstitucional.gov.co/relatoria/1999/t-555-99. htm. Corte Constitucional, Sala Tercera de Revisión, Sentencia T-589-99, 13 de agosto de 1999, expediente T-210000, magistrado ponente Eduardo Cifuentes-Muñoz. Disponible en: http://www.corteconstitucional.gov.co/relatoria/1999/t-589-99.htm. Corte Constitucional, Sala Séptima de Revisión, Sentencia T-1276-05, 6 de diciembre de 2005, expediente T-1166403, magistrado ponente Humberto Antonio Sierra-Porto. Disponible en: http://corteconstitucional. gov.co/relatoria/2005/t-1276-05.htm. Corte Constitucional, Sala Octava de Revisión, Sentencia T-171-06, 7 de marzo de 2006, expediente T-1226076, magistrada ponente Clara Inés VargasHernández. Disponible en: http://www.corteconstitucional.gov.co/relatoria/2006/t-171-06. htm. Corte Constitucional, Sala Novena de Revisión, Sentencia T-077-09, 12 de febrero de 2009, expediente T-1842367, magistrada ponente Clara Inés Vargas-Hernández. Disponible en: http://corteconstitucional.gov.co/relatoria/2009/t-077-09.htm

15 Corte Constitucional, Sala Plena, Auto A227-07, 29 de agosto de 2007, referencia: solicitud de nulidad de la Sentencia T-233 de 2007, proferida por la Sala Quinta de Revisión de Tutelas de la Corte Constitucional, magistrado ponente Marco Gerardo Monroy-Cabra. Expediente: T-1498919. Disponible en: http://www.corteconstitucional.gov.co/relatoria/autos/2007/a227-07. htm. Corte Constitucional, Sala Plena, Sentencia C-610-12, 1 de agosto de 2012, expediente D-8941, magistrado ponente Luis Ernesto Vargas-Silva. http://www.corteconstitucional.gov. co/relatoria/2012/c-610-12.htm. Corte Constitucional, Sala Quinta de Revisión, Sentencia T-555-99, 2 de agosto de 1999, expediente T-197404, magistrado ponente José Gregorio Hernández-Galindo. Disponible en: http://www.corteconstitucional.gov.co/relatoria/1999/t-555-99. htm. Corte Constitucional, Sala Tercera de Revisión, Sentencia T-589-99, 13 de agosto de 1999, expediente T-210000, magistrado ponente Eduardo Cifuentes-Muñoz. Disponible en: http://www.corteconstitucional.gov.co/relatoria/1999/t-589-99.htm. Corte Constitucional, Sala Séptima de Revisión, Sentencia T-1276-05, 6 de diciembre de 2005, expediente T-1166403, magistrado ponente Humberto Antonio Sierra-Porto. Disponible en: http://corteconstitucional. gov.co/relatoria/2005/t-1276-05.htm. Corte Constitucional, Sala Octava de Revisión, Sentencia T-171-06, 7 de marzo de 2006, expediente T-1226076, magistrada ponente Clara Inés VargasHernández. Disponible en: http://www.corteconstitucional.gov.co/relatoria/2006/t-171-06. htm. Corte Constitucional, Sala Novena de Revisión, Sentencia T-077-09, 12 de febrero de 2009, expediente T-1842367, magistrada ponente Clara Inés Vargas-Hernández. Disponible en: http://corteconstitucional.gov.co/relatoria/2009/t-077-09.htm 
Parte del problema jurídico formulado se delimita en el primero de los momentos que destaca la Corte Constitucional como contenido esencial del derecho a la prueba: la etapa o momento de la proposición o requerimiento de la prueba. De aquí la importancia de este ítem en cuanto a su cronología en el contexto del proceso, por ejemplo, el pronunciamiento sobre la admisibilidad de la prueba no es posible sin el debido agotamiento de la etapa de proposición o requerimiento de la prueba; así mismo, no es posible llegar al momento de la valoración o apreciación de las pruebas ${ }^{16}$ conforme a las reglas de la sana crítica, sin el debido agotamiento de la etapa de proposición o requerimiento de la prueba. De esta forma, esta institución que se configura desde la jurisprudencia se hace estructural y, por esta razón, es el criterio de selección de la investigación.

Al respecto, debe indicarse que la principal doctrina nacional no desarrolla en forma exacta el contenido de esta etapa del proceso probatorio bajo la expresión proposición o requerimiento de la prueba, ni su contraste y consecuencias desde el enfoque al derecho a la prueba tal como aquí se propone. Para tal efecto emplea, por ejemplo, dentro de las etapas de la actividad probatoria, los conceptos de proposición y ordenación ${ }^{17}$; o en un contexto de la búsqueda de la producción y la conservación de las pruebas ${ }^{18}$; o dentro de los tres momentos de la actividad probatoria, refiere al momento de conformación de los elementos de juicio o pruebas ${ }^{19}$; o en el enunciado como "camino de la prueba" dentro de las etapas probatorias en la petición y aporte de la prueba ${ }^{20}$; o dentro de las fases de la actividad probatoria en la etapa de solicitud ${ }^{21}$; o como principio del derecho a la prueba, sin hilar el tema respecto a los

16 El examen de esta etapa en el proceso probatorio se excluye del propósito de la investigación. Al respecto, puede consultarse JoRdi NiEva-Fenoll, La valoración de la prueba $\left(1^{\mathrm{a}} \mathrm{ed}\right.$., Marcial Pons, Madrid, 2010).

17 Jaime Azula-Camacho, Manual de derecho procesal. Pruebas judiciales, Vol. IV, 62-63 (3 ${ }^{\mathrm{a}}$ ed., Editorial Temis S.A., Bogotá, 2008).

18 Jeremy Bentham, Tratado de las pruebas judiciales, 525 ( $2^{\text {a }}$ ed., Valletta Ediciones S.R.L., Buenos Aires, 2008).

19 Jordi Ferrer-Beltrán, La valoración racional de la prueba, 41 (1 ${ }^{\mathrm{a}} \mathrm{ed}$., Marcial Pons, Ediciones Jurídicas y Sociales S.A., Madrid, 2007).

20 Nattan Nisimblat-Murillo, Derecho probatorio. Introducción a los medios de prueba en el Código General del Proceso. Principios y medios de prueba en particular, 160 ( $1^{\mathrm{a}} \mathrm{ed}$., Ediciones Doctrina y Ley Ltda., Bogotá, 2013).

21 Ana Giacomette-Ferrer, Teoría general de la prueba $\left(1^{\mathrm{a}} \mathrm{ed} .\right.$, Grupo Editorial Ibáñez, Bogotá, 2015). 
insumos referidos y su importancia en esta etapa ${ }^{22}$; o dentro de las fases y etapas de la actividad probatoria en el proceso en la producción u obtención de la prueba y dentro de esta, la proposición y presentación de la prueba ${ }^{23}$; o dentro de la actividad probatoria dentro de la fase de producción de la prueba ${ }^{24}$; o dentro de la selección de las pruebas, se trata el derecho a presentar pruebas relevantes ${ }^{25}$. Así las cosas, no se perfila en la problemática un estado del arte que ligue la materia con un enfoque constitucional y desde la jurisprudencia de la Corte Constitucional que describió una de las etapas del proceso probatorio en los términos referidos, ni su relación con los enunciados insumos que garantizan el derecho fundamental a la prueba.

A partir de estos resultados que contrastan las diversas disposiciones procesales en Colombia y la jurisprudencia constitucional relevante al punto, es posible afirmar que constituyen insumos que aseguran el derecho a la prueba en la etapa de proposición y requerimiento de la prueba los siguientes: a) la carga de la prueba, b) la inversión de la carga de la prueba, c) la prueba de oficio, d) la carga dinámica de la prueba y e) la medida cautelar probatoria. En otros términos, el juez puede encontrar la verdad, certeza, convicción más allá de toda duda razonable y sinónimos, para quedarse en la noción clásica de la carga de la prueba, o al invertir la carga, $\mathrm{u}$ ordenar de manera oficiosa la prueba de un hecho, o asignar la carga de probar a alguna de las partes, o por medio de una medida cautelar probatoria.

Teniendo en cuenta esto, no es accidental que la Corte Constitucional haya empleado esos dos vocablos, proposición y requerimiento. En el primero de ellos se ubica el insumo de a) la noción clásica de carga de la prueba, y en el segundo los insumos b) la inversión de la carga de la prueba, c) la prueba de oficio, d) la carga dinámica de la prueba y e) la medida cautelar probatoria, dado que al no serle

22 Jairo Parra-Quijano, Manual de derecho probatorio. La prueba en los procedimientos: civil, penal (ordinario y militar), laboral, canónico, contencioso-administrativo y en el derecho comparado, 116-127 (16ª ed., Librería Ediciones del Profesional Ltda., Bogotá, 2007).

23 Hernando Devis-Echandía, Compendio de derecho procesal. Pruebas judiciales, Vol. II, 93-97 ( $8^{\mathrm{a}}$ ed., Editorial ABC, Bogotá, 1984).

24 Benigno Humberto Cabrera-Acosta, Teoría general del proceso y de la prueba (2 ${ }^{\mathrm{a}}$ ed., Librería Jurídicas Wilches, Bogotá, 1988).

25 Michele Taruffo, La prueba ( $1^{\mathrm{a}}$ ed., Marcial Pons, Ediciones Jurídicas y Sociales S.A., Madrid, 2008). 
suficiente al juez lo que le proponen las partes, se necesita para el proceso que se requiera la prueba a ellas o a cualquier otro, a fin de asegurar la prueba de los hechos.

De esta forma, hay un presupuesto fundamental, el derecho a la prueba es una concepción que como derecho fundamental antecede a la noción de carga de la prueba, a la inversión de la carga de la prueba, a la prueba de oficio, a la carga dinámica de la prueba y a la medida cautelar probatoria, las cuales le sirven como instrumento, dado que la garantía del derecho constitucional a la prueba se hace efectiva en uno o en todos aquellos insumos a los que acuda el juez para decidir. Siendo así, el derecho a la prueba posee en el proceso herramientas que garantizan su efectividad, por medio de cada uno de aquellos insumos.

Desde esta perspectiva constitucional y procesal, en los casos concretos, el juez del Estado social de derecho puede percibir - $-\mathrm{y}$ con mayor razón en un proceso oral - con inmediación y contradicción, que es la tipología de proceso que predica el CGP, los vacíos o dudas existentes sobre el acontecer fáctico, para responder con justicia al valorar no solo lo que tiene y es ofertado por las partes, sino al usar los insumos que le garanticen efectivamente el derecho a la prueba. Cuando no se garantiza la búsqueda para la verificación, confirmación, ratificación y sinónimos sobre la ocurrencia de los hechos que se alegan y resisten, se vulnera el derecho a la prueba. Cuando el juez emplea cualquiera de los insumos referidos y ausculta en la búsqueda del medio de prueba, garantiza el derecho a la prueba.

En esta instancia, siguiendo la doctrina especializada es pertinente este cuestionamiento: ¿Tiene legitimidad una sentencia favorable a una parte que se justifica porque la otra, a pesar de existir el hecho que hubiera variado la decisión, no pudo probarlo por lo difícil que le resultaba? ${ }^{26}$ Ante estas realidades, se debe afirmar que el derecho fundamental a la prueba no puede depender de la noción clásica de la carga de la prueba, por cuanto si el hecho existe, este posee otros insumos que hacen efectiva su garantía en el proceso.

A continuación, se presentan los aspectos principales de cada uno de estos insumos esenciales.

26 Jairo Parra-Quijano, Manual de derecho probatorio ( $18^{\mathrm{a}}$ ed., Librería Ediciones del Profesional Ltda., Bogotá, 2011). 


\section{La carga de la prueba o carga estática de la prueba}

Quien alega un hecho debe probarlo, esa es la regla de conducta y juicio incorporada en la noción clásica de la carga de la prueba dentro del proceso judicial. Esta fórmula se transcribió en fiel reproducción del CPC, artículo 177, al CGP, artículo 167, salvo el nuevo inciso segundo atinente a la carga dinámica de la prueba. Debe hacerse precisión en torno a que desde el CC, artículo 1757, se presenta la fórmula referida al señalar "Incumbe probar las obligaciones o su extinción al que alega aquellas o esta"; las disposiciones posteriores establecieron: "Incumbe a las partes probar el supuesto de hecho de las normas que consagran el efecto jurídico que ellas persiguen".

Indiscutiblemente, la carga de la prueba como regla de conducta, en la medida en que le señala a la parte la forma de proceder frente a los hechos que alega y su prueba, y como regla de juicio, mientras le define al juez una u otra forma de sustentar su decisión ${ }^{27}$ frente a la existencia o inexistencia de prueba en el proceso, es y será la piedra angular para la proposición del medio de prueba. Si se alega la ocurrencia de un hecho, quien hace ese ejercicio de enunciación que insinúa a fin de que se le aplique el derecho, debe probar o llevar ante el juez los medios necesarios y pertinentes a fin de que se determine su utilidad en la sentencia, o en términos del Código ${ }^{28}$, debe demostrar los hechos concretos que se ajustan al supuesto general de la norma cuya aplicación se está solicitando ${ }^{29}$. En otros términos — prácticos_-, si se alega que Jennifer es arrendataria, debo probar la existencia de un contrato de arrendamiento; si se alega que Claudia debe cinco millones de pesos, debe probarse que efectivamente se entregó aquella determinada suma de dinero, etc., salvo lo atinente a la novedosa institución del proceso monitorio ${ }^{30}$

27 Hernando Devis-Echandía, Teoría general de la prueba judicial, Vol. I (6 ${ }^{\mathrm{a}}$ ed., Editorial Temis S.A., Pontificia Universidad Javeriana, Bogotá, 2012).

28 Colombia, Ley 1564 de 2012, por medio de la cual se expide el Código General del Proceso, CGP y se dictan otras disposiciones, 48.489 Diario Oficial, 12 de julio de 2012. Disponible en: http://www.secretariasenado.gov.co/senado/basedoc/ley_1564_2012.html

29 Ulises Canosa-SuÁrez, Código General del Proceso. Aspectos probatorios, en Memorias del XXXIII Congreso Colombiano de Derecho Procesal, Cartagena, 12, 13 y 14 de septiembre de 2012, 33-62 (Universidad Libre, Bogotá, 2012). Disponible en: https://letrujil.files.wordpress. com/2012/09/derechoprocesalfinal.pdf

30 Carlos A. Colmenares-Uribe, El procedimiento monitorio en Colombia, en El procedimiento monitorio en América Latina. Pasado, presente y futuro, 109-175 (1 ${ }^{\text {a }}$ ed., JoRdI NIEVA-FenOLL, Rodrigo Rivera-Morales, Juan Pablo Correa-Delcasso \& Carlos A. Colmenares-Uribe, Editorial Temis S.A., Bogotá, 2013). 
establecida en el CGP, por la cual, a partir de la mera enunciación del hecho, sin existencia de prueba sobre la pretensión de pago de suma determinada de dinero, se requiere o intima al deudor por el juez.

\section{a. Discusión y crítica sobre la carga de la prueba o carga estática de la prueba}

La razón por la que la carga de la prueba no es el único insumo al que puede acudir el juez y que justifica la existencia de los otros, está más allá de un conjunto de características propias de un sistema inquisitivo o dispositivo, en el influjo de la realidad y el contexto que se le plantea en el caso concreto al juez del Estado social de derecho.

Cuando el derecho le dice a la persona que busca al juez: le "incumbe probar el supuesto de hecho de las normas que consagran el efecto jurídico que ellas persiguen", es posible que la aplicación de la regla sea contraria al derecho a la prueba. Por ejemplo, en la parte que ostenta la calidad de especial protección constitucional, o en aquella para la cual la adecuación a la norma implica una imposibilidad fáctica y jurídica que trae consigo una condición de desigualdad y de injusticia en el proceso judicial; al imponerse la carga de la prueba a un sujeto que social o económicamente es inferior o se encuentre en clara "desventaja", implica exigirle una "labor que linda con el heroísmo" 31 . Ante estas situaciones repetitivas en la vida, el derecho encontró una solución con el establecimiento de estos otros insumos, en principio por medio de la jurisprudencia y, posteriormente en la Ley.

Ciertamente, al no ser la prueba el problema frente a la pretensión, porque ella existe, sino las deficiencias frente a su búsqueda para la tutela efectiva del derecho y para el encuentro de la justicia, la carga de la prueba se tornó insuficiente. Por ejemplo, por no tener la prueba el demandante que alega el hecho por circunstancias técnicas especiales o por su lejanía con el material probatorio, o por no tener en su poder el objeto de prueba, o simplemente porque no lo

31 Jairo Parra-Quijano, Crisis de la noción clásica de la carga de la prueba, en Memorias XVI Congreso Colombiano de Derecho Procesal, Cali, 6, 7 y 8 de septiembre de 1995, 16-26 (Instituto Colombiano de Derecho Procesal, ICDP, Universidad Libre, Cali, 1995). Disponible en: http://publicacionesicdp.com/index.php/Revistas-icdp/article/view/219/pdf 
puede probar, por cuanto - aunque la prueba exista - esta le falta al proceso y, en consecuencia, priva al demandante del derecho a la prueba, lo cual en casos concretos e hipótesis como las expuestas, puede vaciar el contenido esencial del derecho fundamental.

Con todo, debe aceptarse que la noción clásica de carga de la prueba sigue siendo la regla general dentro del proceso probatorio y que su lógica se obviará como ultima ratio. Sin embargo, resultaría caótico para la justicia, la verdad y el proceso judicial si existiese exclusivamente este insumo como garantía del derecho a la prueba, pues su finalidad claramente identificable con una ideología liberal, desde cierta perspectiva, le señala a la parte que alegue de manera astuta y hábil lo que le convenga, en otro términos que dirija muy bien la enunciación y discurso de los hechos, para que en el caso, a pesar de tener el objeto de prueba como demandante, si el hecho se alega en la excepción, haya falta de prueba y ella resulte impróspera para el demandado a partir de la regla de juicio. Todo esto sin importar los valores de la verdad y la justicia como fin del proceso judicial y que se anclan con garantías constitucionales ${ }^{32}$.

\section{Inversión de la carga de la prueba}

En ciertas circunstancias a pesar de alegarse un hecho conforme a la regla del onus probandi incumbit actori [la carga de la prueba incumbe al actor], i) no puede probarse o ii) "no sabe probarse" o iii) donde el juez fue inactivo de oficio, y no necesariamente debe verse condenada la protección de la pretensión en el proceso. En ciertos casos, injusticias o precisas particularidades de los casos concretos hacen que la regla de conducta y la regla de juicio se inapliquen.

En términos exactos, la inversión de la carga de la prueba puede definirse en los siguientes términos: i) "No incumbe a la parte que alega probar el supuesto de hecho de la norma que consagra el efecto jurídico que ella persigue", ii) "No incumbe probar las obligaciones o su extinción al que alega aquellas o esta", iii) "A quien alega el supuesto de hecho de la norma cuyos efectos jurídicos se persiguen, existencia de una obligación o su extinción, no le incumbe probar".

32 Diana María Ramírez-Carvajal, Una mirada a la prueba en la reforma procesal civil, en Reformas procesales en Colombia y en el mundo, 617-633 (Mónica María Bustamante-Rúa, Universidad de Medellín, Medellín, 2014). 
La prueba de la incapacidad económica, por ejemplo, en los eventos en que se exige el pago de la cuota de remuneración una vez se aprueban o se ordena la autorización de procedimientos, intervenciones y medicamentos excluidos del plan obligatorio de salud $(\mathrm{POS})^{33}$, o frente a la prueba de la afectación del mínimo vital para la compatibilidad de la pensión de invalidez y la pensión de gracia $^{34}$, en ocasiones se presenta suficientemente con la simple declaración indefinida cuando no ha recibido contradicción de la parte o, ahí no hay un criterio uniforme, con un principio de prueba.

La negación indefinida "no tengo capacidad económica" se toma entonces como prueba indiciaria que invierte la carga de la prueba hacia el demandado, porque se presume la buena fe en términos de la referida jurisprudencia. Por lo general, esto es en sede de tutela y en casos semejantes a los narrados, las entidades demandadas resultan tuteladas o, desde otra perspectiva, buscan el soporte suficiente que es la sentencia en sí misma, para así poder otorgar la prestación del servicio y luego recobrar al Fondo de Solidaridad y Garantía del sistema general de seguridad en salud de Colombia, FOSYGA, que puede ser el interés real.

En estos casos concretos, si no se invierte la carga de la prueba, ante la dificultad o imposibilidad de ciertos eventos que según la carga estática de la prueba se debían demostrar, tal como ocurría en los casos de responsabilidad extracontractual del Estado en la actividad médico sanitaria ${ }^{35}$ bajo la tesis de la falla presunta del servicio $^{36}$, "o en algunos casos de simulación, o en los casos en los que se ejerce la acción pauliana — donde el demandante debe probar la intencionalidad del demandado de causarle el agravio o también conocido como el ánimo defraudatorio__" 37 y esto es una forma

33 Corte Constitucional, Sala Sexta de Revisión, Sentencia T-819-03, 18 de septiembre de 2003, expediente T-752 205, magistrado ponente Marco Gerardo Monroy-Cabra. Disponible en: http://www.corteconstitucional.gov.co/relatoria/2003/t-819-03.htm

34 Corte Constitucional, Sala Sexta de Revisión, Sentencia T-653-04, 8 de julio de 2004, expediente T-856266, magistrado ponente Marco Gerardo Monroy-Cabra. Disponible en: http:// www.corteconstitucional.gov.co/relatoria/2004/t-653-04.htm

35 Mario Fernando Parra-Guzmán, Carga de la prueba en la responsabilidad médica ( $1^{\mathrm{a}}$ ed., Ediciones Doctrina y Ley Ltda., Bogotá, 2010).

36 Luis Guillermo Serrano-Escobar, El régimen probatorio en la responsabilidadmédica $\left(1^{\mathrm{a}} \mathrm{ed}\right.$., Ediciones Doctrina y Ley Ltda., Bogotá, 2012).

37 Luis Guillermo Acero-Gallego, La carga de la prueba. Régimen probatorio - Carga de la prueba (Universidad Externado de Colombia, Bogotá, 2 de agosto de 2014). Disponible en: https://www.youtube.com/watch?v=IeAcIguk2UY 
llamativa de denominación de la prueba pero acorde a la realidad, se le estaría exigiendo al accionante una "prueba diabólica", término que ha sido empleado por la Corte Constitucional y sobre el cual se edifica la idea de que la prueba del hecho resulta imposible si se aplica sin más la noción clásica de la carga de la prueba.

Otro caso que ejemplifica la temática se identifica en la jurisprudencia de la Corte Constitucional ${ }^{38}$, cuando la entidad administrativa niega a la persona-víctima la entrega de la ayuda humanitaria de emergencia, porque no probó que los motivos ideológicos de la muerte de su cónyuge se debieron al conflicto armado, sin necesidad de otro calificativo, es este un caso de desafortunada interpretación propio de la vigencia plena del onus probandi incumbit actori, pues cómo podría probarse esta situación, más aún cuando la información que por medio del derecho de petición pueda alcanzarse no obtiene una resolución oportuna para el demandante. Precisamente, la denominación diabólica se justifica, porque si el juez se queda con el concepto de carga del artículo 177 del Decreto 1400 de $1970^{39}$ y 167 inciso 1 de la Ley 1564 de $2012^{40}$, no existe la posibilidad de darle la razón a quien la tiene desde el punto de vista de la Constitución.

\section{a. Discusión y crítica sobre la inversión de la carga de la prueba}

El problema de la inversión de la carga de la prueba radica en qué momento se invierte la carga de probar. Cuando el juez invierte la carga lo hace en la sentencia, es decir, cuando ya no existe posibilidad alguna de defensa por parte del demandado. Por regla general, en la sentencia de una alta Corte se le informa a la parte que debía probar un determinado hecho. Sin duda, podría haber un estado de indefensión del demandado porque, según la regla del derecho

38 Corte Constitucional, Sala Sexta de Revisión, Sentencia T-510-09, 30 de julio de 2009, expediente T-2.137.392, magistrado ponente Jorge Ignacio Pretelt-Chaljub. Disponible en: http:// www.corteconstitucional.gov.co/relatoria/2009/t-510-09.htm

39 Colombia, Decreto 1400 de 1970, por el cual se expide el Código de Procedimiento Civil, CPC, 33.150 Diario Oficial, 21 de septiembre de 1970. Disponible en: http://www.alcaldiabogota. gov.co/sisjur/normas/Normal.jsp?i=6923

40 Colombia, Ley 1564 de 2012, por medio de la cual se expide el Código General del Proceso, CGP y se dictan otras disposiciones, 48.489 Diario Oficial, 12 de julio de 2012. Disponible en: http://www.secretariasenado.gov.co/senado/basedoc/ley_1564_2012.html 
aplicable y según el principio de previsibilidad del derecho, era al demandante a quien le correspondía probar el hecho. Esa sorpresa ${ }^{41}$ no le responde al derecho a la prueba y reviste posibles características de inconstitucionalidad, porque en el afán de descubrir la justicia a uno de los extremos de la relación procesal — demandante - se configuró una clara situación de desventaja en el demandado.

Lo anterior, sin dejar de lado que es indiscutible que la inversión les sirve a innumerables tragedias en la medida en que el demandado en múltiples casos era "estratégicamente" inactivo, teniendo en su poder el objeto de prueba, a fin de resultar victorioso. Sin embargo, la generalización no puede ser la salida o la solución definitiva como si se debiera entonces invertir la carga en todos los casos. Una evidencia clara, consciente o inconsciente en el legislador, de los problemas de la inversión es su no consagración normativa expresa en los nuevos resultados legislativos sobre el proceso. No debe olvidarse que la inversión de la carga de la prueba es, particularmente, una invención de la jurisprudencia, aunque mediante las presunciones legales pueda operar una lógica semejante, son sustancialmente distintas una y otra consagración.

\section{La prueba de oficio}

En el debate sobre la racionalidad e ideología en las pruebas de oficio y el debido proceso contra las pruebas de oficio, que se resume en la discusión sobre si el juez puede o no decretar pruebas, es posible afirmar que posee mayor grado de razón el primero, entre otras, a partir de su reconocimiento expreso en distintos estatutos procesales en el derecho comparado. Desde la insigne obra El juez y la prueba $^{42}$, se evidencia que el problema de la prueba de oficio no es, no será y nunca fue, el de la alteración de la imparcialidad o el de la afectación del principio dispositivo de las partes, dado que se trató de una transcripción errónea del latín por Adolf Eduard Ludwig Gustav Wach (1843-1926) y que luego se transmitió a sus discípu-

41 Jairo Parra-Quijano, Reflexiones sobre algunos aspectos importantes del Código General del Proceso, en Memorias del XXXIII Congreso Colombiano de Derecho Procesal, Cartagena, 12, 13 y 14 de septiembre de 2012, 17-32 (Universidad Libre, Bogotá, 2012). Disponible en: https:// letrujil.files.wordpress.com/2012/09/derechoprocesalfinal.pdf

42 Joan Picó I Junoy, El juez y la prueba. Estudio de la errónea recepción del brocardo 'iudex iudicare debet secundum allegata et probata, non secundum conscientiam' y su repercusión actual (Pontificia Universidad Javeriana, Bogotá, 2011). 
los Konrad Hellwig (1856-1913) y Richard Karl Bernhard Schmidt (1862-1944) y así ininterrumpidamente, aunado a que cuando un juez decreta una prueba desconoce el resultado de la misma y "por ende no puede inclinar la balanza inadecuadamente"43, con lo cual se hace imposible definir qué va a dirigir su intención hacia alguno de los extremos de la relación procesal.

En el CGP se superó la discusión en los términos de los artículos 169 y 170 al reconocerse como un deber del juez el decreto y práctica de pruebas de oficio, lo cual es propio de una ideología que no identifica este actuar como un camino expedito para amparar el descuido o la negligencia de los litigantes como algún sector de la doctrina lo apunta ${ }^{44}$. Esta última perspectiva se considera altamente discutible, porque el proceso judicial no es de los litigantes, debiendo diferenciarse ello del hecho de que la Ley exija el derecho de postulación para que la persona llegue al juez, lo cual es un aspecto que debe distinguirse. En consecuencia, el proceso es de las partes y del juez, no de los abogados; la pretensión y su resistencia son de las partes y el poder de decisión es del juez, no de los abogados.

Cuando el artículo 170 del CGP indica que: el juez "deberá" - con lo cual se modificó el "podrán" del artículo 180 del Decreto 1400 de 1970 - decretar pruebas de oficio cuando sean "necesarias para esclarecer los hechos objeto de la controversia o cuando sean útiles para la verificación de los hechos relacionados con las alegaciones de las partes", evidentemente es porque el actuar del juez se dirige no a burlar la preclusión de los términos probatorios como se suele pensar en el caso en que se toma la oportunidad del decreto de prueba hasta antes de fallar, sino a conocer qué fue lo que realmente ocurrió y con todas las garantías, porque la iniciativa probatoria del juez está sujeta a la contradicción de las partes, tal como se dispone en el inciso final del artículo 170, con lo cual pierde sustento la crítica. Sin duda alguna, este fue un cambio esencial para el proceso judicial en Colombia y el temor que posiblemente había frente a esta institución en relación con la imparcialidad desaparecerá paulatinamente.

43 Carlos Alberto Oliver-Galé, La prueba de oficio: entre activismo y revisionismo. El punto de vista de un juez, 81 (1 $1^{\mathrm{a}}$ ed., Librería Jurídica Sánchez R. Ltda., Medellín, 2010).

44 Armando Jaramillo-Castañeda, Código General del Proceso (1 ${ }^{\mathrm{a}}$ ed., Ediciones Doctrina y Ley Ltda., Bogotá, 2013). 


\section{a. Discusión y crítica sobre la prueba de oficio}

En el proceso penal, en el cual la prohibición del artículo 361 de la Ley 906 de $2004^{45}$ parecía absoluta, porque no puede concebirse que el juez decrete una prueba de oficio dado que el "sistema es acusatorio", la postura se ha atenuado. Desde el juez constitucional ${ }^{46} \mathrm{y}$ frente a las funciones propias del juez de control de garantías, esa plenitud se relativizó, y seguramente en un futuro se superarán los argumentos en virtud de los cuales la prueba de oficio rompe el principio de igualdad de armas y de neutralidad en el proceso penal acusatorio para la etapa del juicio y la audiencia preparatoria.

Debe aclararse que con la expresión "en un futuro" quizás se esté siendo extremista, dado que esa realidad tiene referentes significativos desde la Corte Suprema de Justicia en Sala de Casación Penal, al señalar en sentencia del 30 de marzo de 2006, magistrado ponente Édgar Lombana-Trujillo, previa al pronunciamiento de la Corte Constitucional, una posición mucho más amplia en la existencia de eventuales excepciones a este mandato absoluto, es decir, sobre la posibilidad de que el juez en el proceso penal decrete pruebas de oficio, para lo cual en términos de la decisión: "para ello es imprescindible que el juez argumente razonablemente frente a cada caso concreto que de aplicarse literalmente la restricción contenida en el artículo 361, se producirían efectos incompatibles con la Carta y, por ende, inaceptables"47.

Se comparte esta última posición por cuanto es un análisis que se hace con la Constitución en la mano y no pregonando las características del sistema adversarial. No debe perderse de vista que la reforma hecha a la Constitución ${ }^{48}$ modificó la parte orgánica de la Constitución, no la parte dogmática.

45 Colombia, Ley 906 de 2004, por la cual se expide el Código de Procedimiento Penal, CPP, 45.658 Diario Oficial, 1 de septiembre de 2004. Disponible en: http://www.secretariasenado. gov.co/senado/basedoc/ley_0906_2004.html

46 Corte Constitucional, Sala Plena, Sentencia C-396-07, 23 de mayo de 2007, expediente D-6482, magistrado ponente Marco Gerardo Monroy-Cabra. Disponible en: http://www.corteconstitucional .gov.co/relatoria/2007/C-396-07.htm

47 Corte Suprema de Justicia, Sala de Casación Penal, Sentencia 24468, 30 de marzo de 2006, magistrado ponente Édgar Lombana-Trujillo. Disponible en: http://www.cispa.gov.co/index. php?option=com_docman\&task $=$ doc_download\&gid $=551 \&$ Itemid $=24$

48 Colombia, Acto Legislativo 03 de 2002, por el cual se reforma la Constitución Nacional, 45.040 Diario Oficial, 20 de diciembre de 2002. Disponible en: http://www.secretariasenado.gov.co/ senado/basedoc/acto_legislativo_03_2002.html 
En un caso concreto puede evidenciarse el peligro de la expresión "podrá" de la disposición en la práctica. En un proceso ordinario con pretensión de simulación el juez en primera instancia, cuando ingresó el proceso al despacho para sentencia, se dio cuenta de que hacía falta el registro civil de nacimiento de la única heredera; la solución en aras de la estadística, la más sencilla y ese es el problema de la facultad, decidió no acceder a las pretensiones de la demanda por ausencia de legitimación en la causa. Se apela la decisión y podría pensarse que la situación cambiase, se asumen posturas, y el juez de segunda instancia decreta la nulidad de todo lo actuado a partir del auto que admite la demanda porque se debió haber inadmitido la misma ante la ausencia de uno de los anexos que exigen un medio de prueba específico sobre el presupuesto procesal de capacidad para ser parte. En otros términos, la persona luego de cinco años vio cercenada su razón, porque el material probatorio era contundente en la prueba de la simulación, porque la facultad "podrá" le permite la indiferencia al juez y sin consecuencia alguna para él, aunque incuestionablemente nociva para la parte.

Al postularse como "deber" ciertamente habrá una conciencia más aguda hacia la justicia en aras de definir la situación del derecho, en el ejemplo expuesto realmente no se sabe cuál fue más desafortunada, si la primera o la segunda instancia. En el caso era viable que el juez solicitara la prueba de oficio, había un soporte jurisprudencial en la Corte Suprema de Justicia y con toda seguridad la parte la iba a aportar y así poder decidir de fondo sobre el derecho. El juez tiene que entender, para que la prueba de oficio tenga un resultado como deber, que tiene en sus manos las necesidades y tragedias de la gente y no un examen sobre el manejo de la técnica por el abogado.

Finalmente, debe señalarse que, en todo caso, la jurisprudencia reconocía con anterioridad al CGP la prueba de oficio como un deber para el juez, más que una facultad, luego aquí el CGP lo que realmente hizo fue adoptar una tesis jurisprudencial al punto en que "no hacerlo cuando ello es imperativo da lugar a un error de hecho, susceptible de ser alegado en casación según lo ha conside- 
rado la Corte Suprema de Justicia..." ${ }^{\text {’9 }}$. En sentido semejante, la Corte Constitucional había señalado:

\begin{abstract}
Juez civil. Deber legal de decretar pruebas de oficio
El decreto oficioso de pruebas, en materia civil, no es una atribución o facultad potestativa del Juez: es un verdadero deber legal. En efecto, el funcionario deberá decretar pruebas oficiosamente siempre que, a partir de los hechos narrados por las partes y de los medios de prueba que estas pretendan hacer valer, surja en el funcionario la necesidad de esclarecer espacios oscuros de la controversia; cuando la ley le marque un claro derrotero a seguir; o cuando existan fundadas razones para considerar que su inactividad puede apartar su decisión del sendero de la justicia material. Como lo ha expresado la Corte Suprema de Justicia, la facultad oficiosa del juez deviene en un deber derivado de su papel como director del proceso y de su compromiso por hallar la verdad como presupuesto de la justicia, especialmente, si se toma en cuenta que la ley no impuso límites materiales al decreto de pruebas por parte del juez, como sí ocurre en el caso de las partes ${ }^{50}$.
\end{abstract}

Una evidencia clara en relación con el reconocimiento jurisprudencial realizado en el CGP, se ilustra en la graficación de la siguiente línea jurisprudencial:

49 Consejo de Estado, Sala de lo Contencioso Administrativo, Sección Tercera, Sentencia 22355, 16 de mayo de 2002, Leydi Jazmín Rodríguez Rojas y otros vs. departamento del Casanare y otro, consejero ponente Ricardo Hoyos-Duque. Disponible en: http://www.notinet.com.co/ pedidos/22355.htm. En la cita de esta sentencia, el Consejo de Estado cita a su vez una sentencia del 26 de octubre de 1988 de la Corte Suprema de Justicia.

50 Corte Constitucional, Sala Tercera de Revisión, Sentencia T-264-09, 3 de abril de 2009, expediente T-2.112.744, magistrado ponente Luis Ernesto Vargas-Silva. Disponible en: http:// www.corteconstitucional.gov.co/relatoria/2009/t-264-09.htm 


\section{¿EI decreto y práctica de pruebas de oficio constituye en los casos concretos} un deber o una facultad para el juez? Exceptuando la especialidad penal

\begin{tabular}{|c|c|c|}
\hline Un deber & 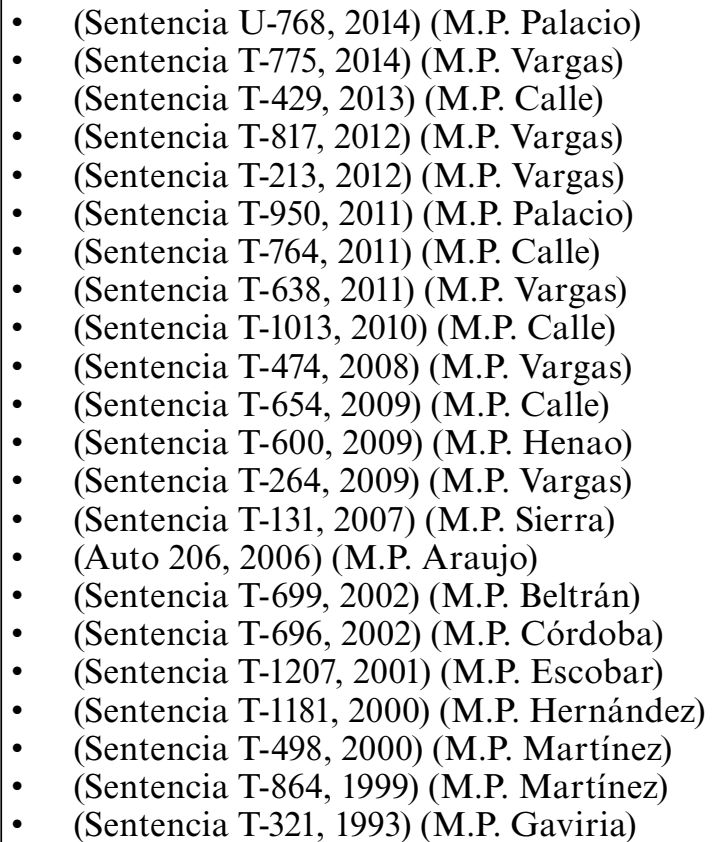 & Una facultad \\
\hline
\end{tabular}

Fuente: elaboración propia

De esta forma, la iniciativa académica reconocida en el Instituto Colombiano de Derecho Procesal, ICDP ${ }^{51}$, y la legislativa correspondiente plasmaron una realidad jurisprudencial, cuya doctrina

51 En relación con la formulación, discusión y desarrollo del Código General del Proceso por el ICDP, previo a su trámite legislativo, puede consultarse el enlace: http://www.icdp.org. co/publicaciones/codigoGeneralDelProceso.html. Así mismo, puede consultarse UlisES Canosa-SuÁrez, Presentación del CGP por el ICDP, en Código General del Proceso: Ley 1564 de 2012 (julio 12), Decreto 1736 de 2012, y notas de constitucionalidad. Comentado, con artículos explicativos de miembros del ICDP, 7-15 (Instituto Colombiano de Derecho Procesal, ICDP, Bogotá, 2014). De igual forma, pueden consultarse las palabras del presidente de la República en la sanción del Código General del Proceso al expresar: "Este Código se basa en el trabajo que desde el año 2004 adelantó el Instituto Colombiano de Derecho Procesal, que elaboró el anteproyecto que luego fue debatido y enriquecido en el mismo gobierno y por la comunidad jurídica en general, en más de 20 foros por todo el país, convocados por el Ministerio de Justicia y el Congreso de la República...”. Juan Manuel Santos-Calderón, Palabras del presidente Juan Manuel Santos en la sanción del Código General del Proceso y del Estatuto de Arbitraje Nacional e Internacional, y posesión de la Ministra de Justicia, Ruth Stella Correa-Palacio (Presidencia de la República, Bogotá, 12 de julio de 2012). Disponible en: http://wsp.presidencia.gov.co/Prensa/2012/Julio/Paginas/20120712_11.aspx 
probable y precedente era claro en términos constitucionales. A pesar de ello, se hacía necesario que fuese la Ley quien expresamente lo indicara, dado que aún para el juez el derecho que se construye en líneas jurisprudenciales se cuestiona, mientras que aquel que viene de la Ley le genera mayor seguridad ${ }^{52}$.

Con todo, hubiese sido pertinente indicar expresamente en la disposición que el decreto de pruebas de oficio no implica prejuzgamiento, tal como aconteció con la disposición atinente al decreto de medidas cautelares en la jurisdicción contencioso administrativa. Allí se indicó en el artículo 229, inciso 2: "la decisión sobre la medida cautelar no implica prejuzgamiento" 53 . Esto con el propósito de que el decreto de pruebas de oficio sea una efectiva realidad procesal, dado que al contemplarlo la Ley - aunque con la jurisprudencia sería suficiente - la aplicación de la institución se independiza de la ideología del juzgador.

\section{La carga dinámica de la prueba}

La disposición pertinente en el CGP, inexistente en el ordenamiento jurídico procesal colombiano previo, señala:

Artículo 167. Carga de la prueba. Incumbe a las partes probar el supuesto de hecho de las normas que consagran el efecto jurídico que ellas persiguen. .

No obstante, según las particularidades del caso, el juez podrá, de oficio o a petición de parte, distribuir la carga al decretar las pruebas, durante su práctica o en cualquier momento del proceso antes de fallar, exigiendo probar determinado hecho a la parte que se encuentre en una situación más favorable para aportar las evidencias o esclarecer los hechos controvertidos. La parte se considerará en mejor posición para probar en virtud de su cercanía con el material probatorio, por tener en su poder el objeto de prueba, por circunstancias técnicas especiales, por haber intervenido directamente en los hechos que

52 En la doctrina a esa corriente que le tema a la verdad, mediante la imposibilidad en la práctica de pruebas de oficio, se le conoce como verifobia y a sus defensores como verifóbicos. $\mathrm{Al}$ respecto, puede consultarse Bruno Cavallone \& Michele Taruffo, Verifobia. Un diálogo sobre prueba y verdad ( $1^{\mathrm{a}}$ ed., Palestra Editores, Lima, 2012).

53 Colombia, Ley 1437 de 2011, por la cual se expide el Código de Procedimiento Administrativo y de lo Contencioso Administrativo, 47.956 Diario Oficial, 18 de enero de 2011. Disponible en: http://www.secretariasenado.gov.co/senado/basedoc/ley_1437_2011.html 
dieron lugar al litigio, o por estado de indefensión o de incapacidad en la cual se encuentre la contraparte, entre otras circunstancias similares.

Cuando el juez adopte esta decisión, que será susceptible de recurso, otorgará a la parte correspondiente el término necesario para aportar o solicitar la respectiva prueba, la cual se someterá a las reglas de contradicción previstas en este código ${ }^{54}$.

En cuanto a la carga dinámica o a lo que la doctrina ha denominado como cargas probatorias dinámicas o distribución de esfuerzos probatorios ${ }^{55}$ o flexibilización probatoria o tendencia aligerante del onus probandi ${ }^{56}$, hay diversas apreciaciones.

\section{a. La carga dinámica de la prueba y su asimilación con el concepto de la inversión de la carga de la prueba: nuestro criterio de investigación que las diferencia}

De la lectura del artículo 167 del CGP y en contraste con el análisis de los antecedentes jurisprudenciales en Colombia sobre la expresión "carga dinámica de la prueba", con anterioridad al CGP y bajo el vocablo "inversión de la carga de la prueba" se desarrolló la lógica probatoria en virtud de la cual un hecho debe ser probado por la parte a la que le queda más fácil probarlo, no por quien lo alegó, tal como ocurre en materia de responsabilidad administrativa

54 Colombia, Ley 1564 de 2012, por medio de la cual se expide el Código General del Proceso, CGP y se dictan otras disposiciones, 48.489 Diario Oficial, 12 de julio de 2012. Disponible en: http://www.secretariasenado.gov.co/senado/basedoc/ley_1564_2012.html

55 Jorge W. Peyrano, La carga de la prueba, en Memorias del XXXIV Congreso Colombiano de Derecho Procesal, Medellín, 11, 12 y 13 de septiembre de 2013, 955-974 (Universidad Pontificia Bolivariana, Medellín, 2013). Disponible en: https://letrujil.files.wordpress. com/2013/09/38jorge-w-peyrano.pdf

56 María Patricia Balanta-Medina, Justicia material en términos de flexibilidad probatoria, en Memorias del XXXIV Congreso Colombiano de Derecho Procesal, 1097-1122 (septiembre de 2013). Disponible en: https://letrujil.files.wordpress.com/2013/09/43maria-patricia-balanta-m. pdf, http://letrujil.com/memorias/xxxiv-congreso-colombiano-derecho-procesal/ 
por la actividad médica ${ }^{57}$ y en numerosa jurisprudencia de la Corte Constitucional frente a la protección de derechos fundamentales ${ }^{58}$.

Desde esta realidad colombiana, al señalarse en la sentencia que determinado hecho no le correspondía probarlo a quien lo alegó, sino a quien esté en mejores condiciones de hacerlo, no siendo este quien alegó el hecho, se comprendía el concepto de la carga dinámica de la prueba y, a su vez, el de la inversión de la carga de la prueba.

Al respecto, consideramos que la noción de la "inversión de la carga de la prueba" es radicalmente disímil a la noción de la "carga dinámica de la prueba", aunque posean elementos comunes. Por esta razón, se enuncian como insumos diferenciables frente a la garantía del derecho fundamental a la prueba en la etapa de proposición y requerimiento de la prueba. El criterio esencial que impide que ambos conceptos se empleen como sinónimos radica en el momento del procedimiento en el que se le indica a la parte que debe probar un determinado hecho: en la inversión, este deber se define en la sentencia; en la carga dinámica, este deber se define en un momento anterior a la sentencia.

Considerar el momento como un aspecto que permite diferenciar un concepto del otro, encuentra plena justificación en la relevancia constitucional del derecho fundamental a la prueba, del cual son titulares tanto el demandante como el demandado. Con anterioridad se afirmó que con la inversión de la carga de la prueba se configuró una clara situación de desventaja para el demandado, por cuanto este solo se enteraba del deber de probar un determinado hecho en la decisión que lo condenaba en última instancia. En la carga dinámica de la prueba, esa particularidad procesal es inexistente, ya que no se sorprende al demandado en la sentencia, y este deber se asigna en un momento previo a ella, con todas las garantías de contradicción y defensa sobre el medio de prueba.

57 Juliana Pérez-Restrepo, La carga dinámica de la prueba en la responsabilidad administrativa por la actividad médica - decaimiento de su aplicabilidad - 68 Revista Estudios de Derecho, 152, 201-225 (julio-diciembre de 2011). Disponible en: http://www.leyex.info/magazines/ vol68n1521.pdf

58 Alberto Rojas-Ríos, La carga dinámica de la prueba en la jurisprudencia de la Corte Constitucional, en Memorias del XXXIV Congreso Colombiano de Derecho Procesal, Medellín, 11, 12 y 13 de septiembre de 2013, 943-953 (Universidad Pontificia Bolivariana, Medellín, 2013). Disponible en: https://letrujil.files.wordpress.com/2013/09/37alberto-rojas-rios.pdf 


\section{b. La carga dinámica de la prueba como facultad: cuestión discutible a partir de una interpretación sistemática del CGP}

De la lectura del inciso que consagra la carga dinámica de la prueba y en contraste con el análisis realizado en materia de la prueba de oficio, aparentemente el legislador quiso que aquella tuviese el mismo proceso de desarrollo que esta al consagrarse como facultad. El artículo 167 de la Ley 1564 de 2012 indica: "el juez 'podrá, de oficio o a petición de parte, distribuir la carga..." refiriéndose así a la carga dinámica de la prueba como facultad. Sin embargo, esta posición debe reconsiderarse con base en el siguiente contexto normativo y posible interpretación sistemática:

El artículo 4 del CGP se refiere a la igualdad de las partes y dispone: "el juez 'debe' hacer uso de los poderes que este código le otorga para lograr la igualdad real de las partes"; así mismo, el numeral 2 del artículo 42 señala: "Son deberes del juez: ... 2. Hacer efectiva la igualdad de las partes en el proceso, usando los poderes que este código le otorga", reitera la existencia de un deber, no de una facultad. De esta forma, por ejemplo, si hay desigualdad material entre las partes como sucede entre el trabajador y el empleador en la relación de trabajo, el juez laboral puede utilizar la herramienta del inciso 2 del artículo 167 porque la igualdad de las partes en el CGP es la igualdad de la Constitución y la de la jurisprudencia constitucional que interpreta el derecho con autoridad, con todas las consecuencias que de allí se desprenden e incluso en el contexto del principio de discriminación positiva debe el juez distribuir la carga como ha sucedido reiteradamente en materia de desplazamiento forzado $^{59}$, entre otras hipótesis ${ }^{60}$.

59 Corte Constitucional, Sala Octava de Revisión, Sentencia T-076-13, 14 de febrero de 2013, expediente T-3417272, magistrado ponente Alexei Egor Julio-Estrada. Disponible en: http:// www.corteconstitucional.gov.co/relatoria/2013/t-076-13.htm

60 Otras providencias que definen la distribución de la carga de la prueba empleando como sinónimas a la inversión de la carga la prueba y la carga dinámica de la prueba en los términos señalados son: Corte Constitucional, Sala Tercera de Revisión, Sentencia T-211-10, 23 de marzo de 2010, expedientes T-2429160 y T-2447275, magistrado ponente Juan Carlos Henao-Pérez. Disponible en: http://www.corteconstitucional.gov.co/relatoria/2010/t-211-10. htm. Corte Constitucional, Sala Tercera de Revisión, Sentencia T-141-11, 4 de marzo de 2011, expediente T-2.815.412, magistrado ponente Juan Carlos Henao-Pérez. Disponible en: http:// www.corteconstitucional.gov.co/relatoria/2011/t-141-11.htm. Corte Constitucional, Sala Quinta de Revisión, Sentencia T-318-11, 4 de mayo de 2011, expediente T-2772734, magistra- 
Ciertamente, la distribución de la carga de la prueba es una institución que persigue la garantía del derecho a la igualdad frente a sucesos que lo desequilibran. En este punto, el CGP le exige al juez nivelar estas situaciones particulares y no simplemente lo faculta. Lo anterior es congruente con lo establecido en el artículo 8 del CGP al referir en la iniciación e impulso de los procesos que: "los jueces 'deben' adelantar los procesos por sí mismos y son responsables de cualquier demora que ocurra en ellos si es ocasionada por negligencia suya". He aquí otro referente del deber.

En esta misma línea, el inciso 1 del artículo 42 sobre los deberes del juez señala: "Son deberes del Juez: 1. Dirigir el proceso, velar por su rápida solución, presidir las audiencias, adoptar las medidas conducentes para impedir la paralización y dilación del proceso y procurar la mayor economía procesal". Adicionalmente, el inciso 4 del artículo 42: "Son deberes del juez: 4. Emplear los poderes que este código le concede en materia de pruebas de oficio para verificar los hechos alegados por las partes". Otros referentes del deber en contraposición de la facultad.

En consecuencia, todos estos parámetros podrían definir, aunque es posible que la literalidad triunfe, que esa facultad puede matizarse y que la jurisprudencia empezará a discutir sobre la carga dinámica de la prueba como deber, tal como sucedió con la prueba de oficio en su época. Infaliblemente, y siguiendo reconocida doctrina en la materia ${ }^{61}$, "la función judicial no puede ser mirada como aquella que cumple su cometido dándole la razón al que mejor administra la técnica del proceso y no al que la tiene en términos de justicia sustancial", que es el fin último de la consagración de estas instituciones, aquí denominadas pedagógicamente insumos de la actividad probatoria en el proceso judicial en la etapa de proposición y requerimiento de la prueba.

\footnotetext{
do ponente Jorge Iván Palacio-Palacio. Disponible en: http://www.corteconstitucional.gov. co/relatoria/2011/t-318-11.htm. Corte Constitucional, Sala Séptima de Revisión, Sentencia T-129-12, 7 de febrero de 2012, expediente T-3.256.073, magistrado ponente Jorge Ignacio Pretelt-Chaljub. Disponible en: http://www.corteconstitucional.gov.co/relatoria/2012/T-129-12. htm. Corte Constitucional, Sala Octava de Revisión, Sentencia T-441-12, 14 de junio de 2012, expediente T-3.302.323, magistrado ponente Humberto Antonio Sierra-Porto. Disponible en: http://www.corteconstitucional.gov.co/relatoria/2012/t-441-12.htm

61 Jairo Parra-Quijano, Derecho procesal civil. Parte general, Vol. I (1 $1^{\text {a }}$ ed., Editorial Temis S.A., Bogotá, 1992).
} 


\section{c. Discusión y crítica sobre la carga dinámica de la prueba}

Hay distintos problemas concretos frente a este insumo, adicionales al referido en la facultad. A pesar de la vigencia diferida de la disposición, se identifican las siguientes cuestiones discutibles:

\section{d. En relación con la exclusiva procedencia del recurso de reposición y la exclusión del recurso de apelación frente al auto que distribuye o niega la distribución de la carga de la prueba}

En lo atinente, el artículo 167 consagra una ambigua exclusividad del recurso procedente cuando el juez: i) distribuya la carga o ii) cuando este se niega a distribuirla. Frente a estos ítems, se considera que no se contempló la hipótesis, viable, en la que el juez no examina con detalle los hechos objeto de prueba y al distribuir la carga vulnera el derecho a la prueba, por serle fácticamente imposible a la parte aportarla. No se cuestiona por alguna parte de la doctrina la no procedencia del recurso de apelación frente a la literal expresión en singular del inciso 3 al señalar que la "decisión será susceptible de recurso", y que se sostiene es en referencia al recurso de reposición ${ }^{62}$.

Sin duda, este acto le exige perfección al juez so pena de transformar la carga dinámica en un impulsor de prueba diabólica; se considera que es posible la procedencia del recurso de apelación al configurarse la hipótesis reseñada, caso en el cual se tipifica la causal del artículo 321, numeral 3 del CGP, por ser un auto que niega el decreto de pruebas. En este escenario, en el que el juez asigna el deber de probar y valora en forma inadecuada las causales definidas para distribuir la carga frente a alguna de las partes, procedería contra la decisión el recurso de apelación, siendo aplicable en su plenitud la conocida expresión doctrinal "tanto vale no tener un derecho como no poder ejercerlo o defenderlo"63.

62 Jairo Parra-Quijano, Reflexiones sobre algunos aspectos importantes del Código General del Proceso, en Memorias del XXXIII Congreso Colombiano de Derecho Procesal, Cartagena, 12, 13 y 14 de septiembre de 2012, 17-32, 32 (Universidad Libre, Bogotá, 2012). Disponible en: https://letrujil.files.wordpress.com/2012/09/derechoprocesalfinal.pdf

63 Hernando Devis-Echandía, Nociones generales de derecho procesal civil (2a ed., Editorial 
Al respecto y en aras de plantear las distintas aristas sobre este punto de derecho, resulta oportuno destacar la postura de Nattan Nisimblat al defender la improcedencia del recurso de apelación. Según este, procede el recurso de reposición "mas no el de apelación por no haberlo contemplado así el art. 167 ni el 321 del CGP, pues si bien en el numeral 3 del último de los artículos citados se contempla el recurso de alzada contra el auto que 'niegue el decreto o la práctica de pruebas', no se entiende que la decisión de distribuir la carga de la prueba haga parte de esa clase de decisiones, pues se entiende que, contrario a negar una prueba, lo que impulsa dicho auto es precisamente lo contrario, esto es, mayor actividad respecto de quien en principio no tenía la responsabilidad probatoria en el proceso" ${ }^{6}$. Se perfilan así tesis contrarias sobre el mismo punto de derecho.

\section{e. En relación con el momento procesal límite en el que el juez es competente para distribuir la carga de la prueba: esencia de la etapa de instrucción y juzgamiento}

La disposición establece que se puede distribuir la carga hasta "antes de fallar". Al respecto, debe precisarse lo siguiente:

En el contexto del proceso verbal, el artículo 373 del CGP desarrolla la "Audiencia de instrucción y juzgamiento", un momento procesal en el que son claramente diferenciables tres eventos (no debe olvidarse que se está en audiencia):

1. Se practican las pruebas, posteriormente se oyen los alegatos de las partes y el juez profiere sentencia en forma oral. En esta hipótesis, los actos son sucesivos e ininterrumpidos.

2. Se practican las pruebas, posteriormente se oyen los alegatos de las partes y el juez no profiere sentencia como acto seguido; en este evento, el juez — una vez oídos los alegatos

Temis S.A., Bogotá, 2009).

64 Nattan Nisimblat-Murillo, Derecho probatorio. Introducción a los medios de prueba en el Código General del Proceso. Principios y medios de prueba en particular, $182\left(1^{\mathrm{a}} \mathrm{ed}\right.$., Ediciones Doctrina y Ley Ltda., Bogotá, 2013). 
de las partes - decreta un receso de hasta dos horas para el pronunciamiento de la sentencia en forma oral. En esta hipótesis, los actos son sucesivos e interrumpidos.

3. Se practican las pruebas, posteriormente se oyen los alegatos de las partes y el juez no profiere sentencia como acto seguido; en este evento, el juez — una vez oídos los alegatos de las partes-, anuncia el sentido del fallo y dentro de los diez (10) días siguientes debe pronunciar su sentencia en forma escrita. En esta hipótesis, los actos son sucesivos e interrumpidos.

Esta lógica en la que se contemplan distintos eventos es razonable en el entendido de que no todos los casos que se le presentan al juez son iguales y dependiendo de ese criterio uno u otro tendrá vigencia en el caso. La hipótesis 1 es para los "casos fáciles", por ejemplo, en los que la valoración del medio probatorio sea meramente documental, debiendo hacerse la respectiva salvedad; la hipótesis 2 se tipifica para los "casos moderados", por ejemplo, en los que la valoración de los medios probatorios exige cierto análisis para entretejer sólidamente la ratio decidendi; y la hipótesis 3 se encuadra para los "casos difíciles", tanto así que se sacrifica la oralidad de la sentencia porque no es posible dictarla en esta forma.

Se considera que permitirle al juez exigir que una de las partes pruebe un determinado hecho, con posterioridad al anuncio del sentido de su fallo o al decreto del receso para proferir sentencia, según lo dispuesto en los eventos definidos en el artículo 373 del CGP, avala una mala práctica judicial, en lo que se considera una transgresión a la estructura del proceso conforme al principio de la preclusión de las etapas procesales, pues el juez se entera de lo que va a ocurrir frente al derecho cuando el proceso entra al despacho y va a proferir sentencia. Esta postura - la cual avala la distribución de la carga aun con posterioridad al sentido del fallo o el decreto del receso-implícitamente reconoce una desconfianza en la real efectividad de los pilares del código, en la inmediación, en la concentración, en la oralidad, porque si el proceso se desarrolla en atención plena a ellos, cuando el juez en la audiencia inicial, dentro de un proceso verbal, decreta pruebas y fija los hechos objeto del litigio, y en la audiencia de instrucción donde los fija nuevamente y practica las pruebas decretadas, ello debe ser actuación suficiente 
para dar por agotado el debate probatorio, por lo cual debería entenderse el juzgamiento como una etapa ajena a cualquier forma de retorno o decisión distinta a la sentencia.

En consecuencia, en el evento 1, la etapa de instrucción se extingue una vez se oyen los alegatos de las partes; en el evento 2, la etapa de instrucción se extingue una vez se decreta el receso; en el evento 3, la etapa de instrucción se extingue una vez se anuncia el sentido del fallo; en otros términos, el juez es competente para distribuir la carga de la prueba: en el evento 1, hasta una vez oídos los alegatos; en el evento 2, hasta antes de decretar el receso; en el evento 3, hasta antes de anunciar el sentido de su fallo. Una vez se oyen los alegatos o se decreta el receso o se anuncia el sentido del fallo, se abre la etapa de juzgamiento, en la que solo es posible el pronunciamiento de la sentencia.

\section{f. En relación con la consecuencia jurídica frente al incumplimiento del deber asignado a la parte al distribuirsele la carga de la prueba}

La disposición del artículo 167 no establece consecuencia jurídica expresa en torno al evento en el que el juez asigna la carga de probar a alguna de las partes y esta incumple su orden. Se puede considerar que en este caso se aplicaría la regla de conducta y juicio propia a la noción clásica de carga de la prueba, por lo cual el juez tendría que dar por no probado el hecho, con la consecuencia automática sobre el presupuesto de la pretensión "prueba debida de los hechos".

Al respecto y en aras de plantear las distintas posturas sobre este punto de derecho, resulta oportuno destacar la postura de Luis Guillermo Acero-Gallego al defender la imposibilidad en la aplicación de la regla referida. Según este autor y a partir de la complejidad de la actividad probatoria de los jueces que implica la combinación de los sistemas de carga estática y carga dinámica de la prueba, “...no son claras las consecuencias de una situación de déficit probatorio una vez el juez ha ordenado que ciertos supuestos fácticos sean demostrados por alguna de las partes aplicando para el efecto el sistema de cargas dinámicas”, para lo cual afirma que "...a primera vista, surge que el sistema de cargas dinámicas no puede funcionar igual que el sistema de cargas estáticas, ...y, 
por ende, no es factible entender que el primero contenga también una regla de juicio frente al incumplimiento de la carga impuesta por el juez" "65. Se perfilan así tesis contrarias sobre el mismo punto de derecho.

En consecuencia, la inversión de la carga de la prueba y la carga dinámica de la prueba describen realidades distintas. Son dos conceptos diferentes y por eso se describen como "insumos" independientes, aunque se asemejen en la lógica de asignar la carga a quien le quede más fácil o para proteger a la parte más débil de la relación procesal ${ }^{66}$. La diferencia radica en que la carga dinámica ofrece un momento previo a la sentencia para asignar la carga de probar. En este sentido, los contenidos esenciales de la carga dinámica de la prueba son: i) se distribuye la carga en un momento anterior a la sentencia, con el límite en la competencia del juez en los eventos de casos fáciles, moderados y difíciles, ii) hay un auto del juez que asigna la carga de probar, iii) hay hipótesis específicas sobre las cuales se hace procedente la distribución de la carga, iv) se garantiza el derecho de defensa de las partes, sin privilegiar extremo alguno de la relación procesal, v) el auto es susceptible de recurso de reposición, con la particularidad reseñada respecto del evento en el que sería procedente el recurso de apelación.

\section{La medida cautelar probatoria}

El Estatuto de Arbitraje Nacional e Internacional ${ }^{67}$, conocido también como Ley Fernando Hinestrosa, expedido el mismo día que el CGP, en el parágrafo del artículo 32 desarrolla la medida cautelar probatoria. Al respecto, indica:

65 Luis Guillermo Acero-Gallego, Modificación al régimen de la carga de la prueba en el Código General del Proceso, en El proceso civil a partir del Código General del Proceso, 187-220 ( $1^{\mathrm{a}} \mathrm{ed}$., Horacio Cruz-Tejada, coord., Universidad de Los Andes, Bogotá, 2014).

66 Ana Giacomette-Ferrer, Teoría general de la prueba judicial $\left(1^{\mathrm{a}}\right.$ ed., Consejo Superior de la Judicatura, Bogotá, 2003).

67 Colombia, Ley 1563 de 2012, por medio de la cual se expide el Estatuto de Arbitraje Nacional e Internacional y se dictan otras disposiciones, 48.489 Diario Oficial, 12 de julio de 2012. Disponible en: http://www.secretariasenado.gov.co/senado/basedoc/ley_1563_2012.html 
Las medidas cautelares también podrán tener como objeto recaudar elementos de prueba que pudiesen ser relevantes y pertinentes para la controversia.

Quien ejerza funciones jurisdiccionales podrá decretar medidas cautelares para este propósito en los procesos sometidos a su conocimiento, sean o no procesos arbitrales.

De esta forma, en virtud de esta disposición vigente, el juez puede decir: "los documentos que están en esa caja fuerte me los entregan o ponerles un sello, entre otras" ${ }^{\prime}$. Ciertamente, a pesar de que se trata de una Ley que regula una materia concreta, la disposición habilita para que esta medida cautelar se aplique a todas las especialidades del derecho y respecto de cualquier jurisdicción sin distinción alguna, medida que sin lugar a dudas constituye otro insumo que garantiza el derecho fundamental a la prueba en el proceso.

En lo más destacado debe afirmarse que conforme algún sector de la doctrina las medidas cautelares referentes al aseguramiento de pruebas no son medidas cautelares y se les denomina pruebas anticipadas $^{69}$.

\section{a. Discusión y crítica sobre la medida cautelar probatoria}

Este es el insumo más poderoso, junto a la inversión de la carga y la prueba de oficio, que posee el juez para garantizar el derecho a la prueba en el proceso, por cuanto aquí el juez no se vale de carácter externo alguno en la búsqueda de la prueba y lo hace directamente, lo cual no acontece en la carga de la prueba y la carga dinámica de la prueba, en las que sí se vale de las partes para la búsqueda de la prueba. Frente a esta figura, se presenta un aspecto particular en relación con la lógica del fumus boni iuris y del periculum in mora ${ }^{70}$, que en esta medida cautelar pareciera no ser la misma que la apli-

68 Ramiro Bejarano-Guzmán, Régimen probatorio (Universidad de Los Andes, Bogotá, 18 de febrero de 2013). Disponible en: https://www.youtube.com/watch?v=Wzqsu-bT2YM

69 Jorge Fábrega, Medidas cautelares (1ª ed., Ediciones Jurídicas Gustavo Ibáñez Ltda., Bogotá, 1998).

70 Jordi Nieva-Fenoll, El elemento psicológico en la adopción de las medidas cautelares, en Memorias del IX Congreso Internacional de Derecho Procesal, San José de Cúcuta, 2 y 3 de agosto de 2013, 107-128 (Universidad Libre Seccional Cúcuta, Cúcuta, 2013). 
cable a las medidas cautelares tradicionales y a las innominadas, lo cual plantea la necesidad de que se desarrolle un estudio profundo en la materia frente a la determinación de sus contenidos esenciales.

Finalmente, en lo pertinente al problema formulado y la medida cautelar probatoria, su importancia para esta investigación radica en su indefectible configuración dentro de los insumos integrantes de la garantía del derecho fundamental a la prueba en la etapa de proposición y requerimiento de la prueba, un aspecto que la principal doctrina nacional y extranjera no reconoce desde el enfoque que se aborda en la presente investigación ${ }^{71}$, lo cual permite la abstracción de temas propios y conexos a esta materia tales como las pruebas, los distintos mecanismos coactivos de obtención de prueba, entre otros.

71 En el examen de la más importante doctrina nacional y alguna internacional, no se observa un estudio específico sobre la etapa de proposición y requerimiento de la prueba, ni se aborda un problema a partir de las garantías que le aseguran la prueba al proceso, de allí la imposibilidad de abordar cada insumo en forma extensa dado que uno de los propósitos esenciales de la investigación es evidenciar la reconfiguración del derecho a la prueba frente a la búsqueda de la prueba en el proceso, a partir de la entrada en vigencia del CGP. En esta doctrina se destacan Marina Gascón-Abellán, Cuestiones probatorias, Vol. 61 (1 $1^{\mathrm{a}}$ ed., Serie de teoría jurídica y filosofía del derecho, Universidad Externado de Colombia, Bogotá, 2012). Otтo Tschadek, La prueba, Vol. 9 ( $2^{\mathrm{a}}$ ed., Editorial Temis S.A., Bogotá, 2010). Luis MuñozSABATÉ, La prueba de la simulación ( $3^{\mathrm{a}}$ ed., Editorial Temis S.A., Bogotá, 2011). ANTONIO Dellepiane, Nueva teoría de la prueba ( $9^{\mathrm{a}}$ ed., Editorial Temis S.A., Bogotá, 2003). Marina GASCón-Abellán, Los hechos en el derecho. Bases argumentales de la prueba $\left(2^{\mathrm{a}} \mathrm{ed}\right.$., Marcial Pons, Ediciones Jurídicas y Sociales S.A., Madrid, 2004). Francesco Carnelutti, El concepto jurídico de la prueba ( $1^{\mathrm{a}}$ ed., Editorial Leyer, Bogotá, 2007). Valentín Silva-Melero, La prueba procesal, Vol. I (1 $1^{\text {a }}$ ed., Editorial Revista de Derecho Privado, Madrid, 1963). Adolfo Alvarado-Velloso, La prueba judicial. Reflexiones críticas sobre la confirmación procesal $\left(1^{\mathrm{a}}\right.$ ed., Editorial Universidad del Rosario, Bogotá, 2010). Michele TARuffo, Teoría de la prueba $\left(1^{\text {a }}\right.$ ed., ARA Editores E.I.R.L., Lima, 2012). Al respecto, debe señalarse que recientemente fue publicado un libro que desarrolla el tema del derecho a la prueba en forma amplia, aunque no desde el enfoque de la presente investigación. Miguel EnRIQue Rojas-Gómez, Lecciones de derecho procesal, Vol. III ( $1^{\text {a }}$ ed., Escuela de Actualización Jurídica, ESAJU, Bogotá, 2015). 


\section{CONCLUSIONES}

Los contenidos esenciales del derecho fundamental a la prueba en el proceso judicial colombiano, en la etapa de proposición y requerimiento de la prueba, se describen bajo la vigencia de las instituciones en la noción clásica de la i) carga de la prueba o carga estática de la prueba, ii) la inversión de la carga de la prueba, iii) la prueba de oficio, iv) la carga dinámica de la prueba y v) la medida cautelar probatoria. Estos son los insumos a los que puede acudir el juez que persigue la protección efectiva del derecho a la prueba en un caso concreto. El establecimiento de la carga dinámica de la prueba en la descripción del artículo 167 del CGP constituye, sin duda, una evolución que amplía la garantía del derecho fundamental a la prueba.

El derecho a la prueba no privilegia ninguno de los extremos de la relación procesal. Dependiendo del caso concreto, la noción clásica de la carga de la prueba perjudica al demandante al enfrentarlo a la configuración de una prueba diabólica. Así mismo, la inversión de la carga que sorprende en la sentencia, perjudica al demandado al configurar un deber que conforme a la regla aplicable y previsible no le correspondía. Ante estos extremos y las deficiencias de la mera proposición de la prueba, la prueba de oficio, la carga dinámica de la prueba y la medida cautelar probatoria equilibran las particularidades de desventaja que ella genera, alcanzando la igualdad entre las partes cuando el juez emplea su poder de requerimiento de la prueba.

La inversión de la carga de la prueba es una regla jurisprudencial que reviste serios problemas de inconstitucionalidad, frente al derecho fundamental a la prueba del demandado.

La inversión de la carga de la prueba y la carga dinámica de la prueba describen realidades distintas. Son dos conceptos diferentes y por eso se describen como "insumos" independientes, aunque se asemejen en la lógica de asignar la carga a quien le quede más fácil o para proteger a la parte más débil de la relación procesal ${ }^{72}$. La diferencia esencial radica en que la carga dinámica ofrece un momento previo a la sentencia para asignar la carga de probar.

72 Ana Giacomette-Ferrer, Teoría general de la prueba judicial ( $1^{\mathrm{a}}$ ed., Consejo Superior de la Judicatura, Bogotá, 2003). 
Los contenidos esenciales de la carga dinámica de la prueba son: i) se distribuye la carga en un momento anterior a la sentencia, con el límite en la competencia del juez en los eventos de casos fáciles, moderados y difíciles, ii) hay un auto del juez que asigna la carga de probar, iii) hay hipótesis específicas sobre las cuales se hace procedente la distribución de la carga, iv) se garantiza el derecho de defensa de las partes, sin privilegiar extremo alguno, v) el auto es susceptible de recurso de reposición, con la particularidad reseñada respecto del evento en el que sería procedente el recurso de apelación.

El inciso 2 del artículo 167 del CGP debe ser interpretado en forma sistemática para no caer en el extremismo de la necesidad de una reforma legal respecto de ciertos asuntos, como podría pensarse en materia laboral frente a una lista taxativa que señale los hechos que deben probarse por el empleador o el trabajador. Del estudio del CGP en los artículos 4 y 42, este último en sus numerales 1 y 2 , se identifica el deber del juez en el uso de los poderes que el Código le otorga para lograr la igualdad real y efectiva de las partes y su deber y responsabilidad en el impulso del proceso por medio de las medidas conducentes para impedir su paralización y dilación. Una medida conducente sin duda es la distribución de la carga para verificar los hechos alegados, lo cual es aplicable a cualquier especialidad del proceso judicial —administrativo, laboral...-.

La carga dinámica de la prueba se consagró como una facultad en el CGP; sin embargo, al igual que ocurrió con la prueba de oficio, para la cual la Ley estableció igual característica en el CPC, es probable que conforme a un estudio sistemático de los deberes del juez en el CGP, su decreto se empiece a entender como un auténtico deber por parte de la jurisprudencia.

Ante la inexistente referencia en prohibición expresa del artículo 167 inciso 3 frente a la no procedencia del recurso de apelación, en clara interpretación del artículo 321.4 del CGP, es posible predicar su procedencia contra la decisión del juez que, bajo hipótesis viable, i) niega la distribución de la carga de la prueba o ii) en la que al distribuir la carga en su decisión, vulnere el derecho a la prueba, por serle fácticamente imposible a la parte a la que se le asignó la carga, aportar la prueba del hecho. Esta interpretación es posible, por cuanto al negarse la asignación de la carga o imponerse la mis- 
ma sin cumplir los requisitos del artículo 167, se vulnera el derecho a la prueba al impedirse la práctica de una prueba que por imposibilidad fáctica es difícil o diabólica en su proposición por la parte.

Frente a la posible no procedencia del recurso de apelación, se considera surge la acción de tutela como mecanismo excepcional y subsidiario de defensa judicial, una vez resuelto el recurso de reposición, siendo el auto que distribuye la carga de la prueba pero que impone un actuar heroico, a manera de prueba imposible, y el que niega la distribución de la carga, objeto de tutela como garantía del derecho a la prueba y al debido proceso, siempre que se cumplan los requisitos exigidos por la jurisprudencia constitucional, siendo procedente bajo el alegato de la causal de procedibilidad específica por defecto fáctico.

En vigencia óptima del proceso oral, concentrado, con inmediación y contradicción, el momento más adecuado para distribuir la carga de la prueba en el proceso verbal, se identifica una vez oídos los alegatos de las partes, en la hipótesis de los "casos fáciles", porque en ese instante se extingue la etapa de instrucción, y en el juzgamiento adquiere plena vigencia la necesaria garantía de la preclusión de las etapas procesales. En la hipótesis de los "casos moderados", el límite se identifica al decretar el juez el receso, una vez emitido este auto se agota la etapa de instrucción y empieza la de juzgamiento, en la que solo es posible la sentencia oral. En la hipótesis de los "casos difíciles", el límite se identifica al emitir el juez el sentido del fallo, una vez proferida esta providencia - auto interlocutorio y no una nueva categoría de decisión judicial— precluye la etapa de instrucción e inicia la de juzgamiento, en la que solo es posible la emisión de la sentencia escrita. Una vez se decreta el receso o se profiere el sentido del fallo, no puede decretarse prueba de oficio o distribuirse la carga de la prueba, a partir de la preclusión de las etapas procesales.

Finalmente, el juez tiene que entender, para que la carga dinámica de la prueba y demás insumos y contenidos esenciales del derecho a la prueba - carga de la prueba, prueba de oficio, inversión de la carga de la prueba y medida cautelar probatoria - sean efectivos, que tiene en sus manos las necesidades y tragedias de la gente y no un examen en el manejo de la técnica, astucia, negligencia o 
descuido del abogado. El proceso judicial no es de los abogados, les pertenece a las partes y al juez.

La norma del artículo 167 no establece consecuencia jurídica alguna en torno al evento en el que el juez asigna la carga de probar a alguna de las partes y esta incumple su orden. Se considera que en este caso se aplicaría la regla de conducta y juicio propia a la noción clásica de carga de la prueba, por lo cual el juez tendría que dar por no probado el hecho, con la consecuencia automática sobre el presupuesto de la pretensión "prueba debida de los hechos". 


\section{BIBLIOGRAFÍA}

\section{Libros}

Alvarado-Velloso, Adolfo, Debido proceso versus pruebas de oficio (1 ${ }^{\mathrm{a}} \mathrm{ed}$., Editorial Temis S.A., Bogotá, 2004).

Alvarado-Velloso, Adolfo, La prueba judicial. Reflexiones críticas sobre la confirmación procesal ( $1^{\text {a }}$ ed., Editorial Universidad del Rosario, Bogotá, 2010).

Azula-Camacho, Jaime, Manual de derecho procesal. Pruebas judiciales, Vol. IV ( $3^{\mathrm{a}}$ ed., Editorial Temis S.A., Bogotá, 2008).

Bentham, Jeremy, Tratado de las pruebas judiciales ( $2^{\mathrm{a}}$ ed., Valletta Ediciones S.R.L., Buenos Aires, 2008).

Cabrera-Acosta, Benigno Humberto, Teoría general del proceso y de la prueba ( $2^{\mathrm{a}}$ ed., Librería Jurídicas Wilches, Bogotá, 1988).

Carnelutti, Francesco, El concepto jurídico de la prueba (1 ${ }^{\mathrm{a}}$ ed., Editorial Leyer, Bogotá, 2007).

Cavallone, Bruno \& Taruffo, Michele, Verifobia. Un diálogo sobre prueba y verdad $\left(1^{\mathrm{a}}\right.$ ed., Palestra Editores, Lima, 2012).

DamašKa, Mirjan R., Las caras de la justicia y el poder del Estado (1ª ed., Editorial Jurídica de Chile, Santiago de Chile, 2000). Disponible en: https://books.google. com.co/books?id=1A4MqsNMfMAC\&pg=PA1\&lpg=PA1\&dq=Las+caras $+\mathrm{de}+$

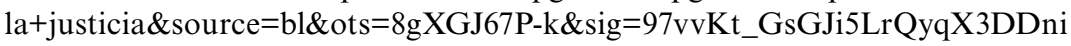
0iA\&hl=es\&sa=X\&ved=0CC8Q6AEwA2oVChMIw_qJmqTqyAIVyBceCh0xZQ $\mathrm{Ih} \# \mathrm{v}=$ onepage $\& \mathrm{q}=\mathrm{Las} \% 20 \operatorname{caras}^{\circ} \% 20 \mathrm{de} \% 201 \mathrm{a} \% 20 \mathrm{justicia} \& \mathrm{f}=\mathrm{f}$

Dellepiane, Antonio, Nueva teoría de la prueba ( $9^{\mathrm{a}}$ ed., Editorial Temis S.A., Bogotá, 2003).

Devis-Echandía, Hernando, Compendio de derecho procesal. Pruebas judiciales, Vol. II ( $8^{a}$ ed., Editorial ABC, Bogotá, 1984).

Devis-Echandía, Hernando, Nociones generales de derecho procesal civil (2 ${ }^{\mathrm{a}}$ ed., Editorial Temis S.A., Bogotá, 2009).

Devis-Echandía, Hernando, Teoría general de la prueba judicial, Vol. I (6 ${ }^{\mathrm{a}}$ ed., Editorial Temis S.A., Pontificia Universidad Javeriana, Bogotá, 2012).

FÁBREGA, JoRge, Medidas cautelares (1 $1^{a}$ ed., Ediciones Jurídicas Gustavo Ibáñez Ltda., Bogotá, 1998).

Ferrer-Beltrán, Jordi, La valoración racional de la prueba $\left(1^{\mathrm{a}}\right.$ ed., Marcial Pons, Ediciones Jurídicas y Sociales S.A., Madrid, 2007).

Gascón-Abellán, Marina, Cuestiones probatorias, Vol. 61 ( $1^{\mathrm{a}}$ ed., Serie de teoría jurídica y filosofía del derecho, Universidad Externado de Colombia, Bogotá, 2012).

Gascón-Abellán, Marina, Los hechos en el derecho. Bases argumentales de la prueba (2a ed., Marcial Pons, Ediciones Jurídicas y Sociales S.A., Madrid, 2004).

Giacomette-Ferrer, Ana, Teoría general de la prueba (1 $1^{\mathrm{a}}$ ed., Grupo Editorial Ibáñez, 
Bogotá, 2015).

Giacomette-Ferrer, AnA, Teoría general de la prueba judicial $\left(1^{\mathrm{a}}\right.$ ed., Consejo Superior de la Judicatura, Bogotá, 2003).

Jaramillo-Castañeda, Armando, Código General del Proceso $\left(1^{\mathrm{a}}\right.$ ed., Ediciones Doctrina y Ley Ltda., Bogotá, 2013).

Muñoz-SABATÉ, Luis, La prueba de la simulación ( $3^{\mathrm{a}}$ ed., Editorial Temis S.A., Bogotá, 2011).

Nieva-Fenoll, Jordi, La valoración de la prueba (1 $1^{\text {a }}$ ed., Marcial Pons, Madrid, 2010).

Nisimblat-Murillo, Nattan, Derecho probatorio. Introducción a los medios de prueba en el Código General del Proceso. Principios y medios de prueba en particular $\left(1^{\mathrm{a}}\right.$ ed., Ediciones Doctrina y Ley Ltda., Bogotá, 2013).

Oliver-Galé, Carlos Alberto, La prueba de oficio: entre activismo y revisionismo. El punto de vista de un juez ( $1^{\mathrm{a}}$ ed., Librería Jurídica Sánchez R. Ltda., Medellín, 2010).

Parra-Guzmán, Mario Fernando, Carga de la prueba en la responsabilidad médica $\left(1^{\mathrm{a}}\right.$ ed., Ediciones Doctrina y Ley Ltda., Bogotá, 2010).

Parra-Quijano, Jairo, Derecho procesal civil. Parte general, Vol. I (1 ${ }^{\text {a }}$ ed., Editorial Temis S.A., Bogotá, 1992).

Parra-Quijano, Jairo, Manual de derecho probatorio (18 ${ }^{\mathrm{a}}$ ed., Librería Ediciones del Profesional Ltda., Bogotá, 2011).

Parra-Quijano, Jairo, Manual de derecho probatorio. La prueba en los procedimientos: civil, penal (ordinario y militar), laboral, canónico, contencioso-administrativo $y$ en el derecho comparado (16 ${ }^{\mathrm{a}}$ ed., Librería Ediciones del Profesional Ltda., Bogotá, 2007).

Parra-QuiJano, Jairo, Racionalidad e ideología en las pruebas de oficio (1 ${ }^{\mathrm{a}}$ ed., Editorial Temis S.A., Bogotá, 2004).

PICÓ I JunOY, JOAN, El juez y la prueba. Estudio de la errónea recepción del brocardo ‘iudex iudicare debet secundum allegata et probata, non secundum conscientiam' y su repercusión actual (Pontificia Universidad Javeriana, Bogotá, 2011).

Ramírez-CARVAJAL, Diana María, La prueba en el proceso. Una aventura intelectual ( $1^{\mathrm{a}}$ ed., Librería Jurídica Sánchez R. Ltda., Medellín, 2013).

Rojas-Gómez, Miguel Enrique, Lecciones de derecho procesal, Vol. III (1 ${ }^{\mathrm{a}}$ ed., Escuela de Actualización Jurídica, ESAJU, Bogotá, 2015).

Serrano-Escobar, Luis Guillermo, El régimen probatorio en la responsabilidad médica ( $1^{a}$ ed., Ediciones Doctrina y Ley Ltda., Bogotá, 2012).

Silva-Melero, Valentín, La prueba procesal, Vol. I (1 ${ }^{\mathrm{a}}$ ed., Editorial Revista de Derecho Privado, Madrid, 1963).

Taruffo, Michele, La prueba (1ª ed., Marcial Pons, Ediciones Jurídicas y Sociales S.A., Madrid, 2008).

TAruffo, Michele, Teoría de la prueba (1ª ed., ARA Editores E.I.R.L., Lima, 2012).

Tschadek, Отto, La prueba, Vol. 9 (2ª ed., Editorial Temis S.A., Bogotá, 2010). 


\section{Colaboración en obras colectivas}

Acero-Gallego, Luis Guillermo, Modificación al régimen de la carga de la prueba en el Código General del Proceso, en El proceso civil a partir del Código General del Proceso, 187-220 ( $1^{\mathrm{a}}$ ed., Horacio Cruz-Tejada, coord., Universidad de Los Andes, Bogotá, 2014).

Balanta-Medina, María Patricia, Justicia material en términos de flexibilidad probatoria, en Memorias del XXXIV Congreso Colombiano de Derecho Procesal, Medellín, 11, 12 y 13 de septiembre de 2013, 1097-1122 (Universidad Pontificia Bolivariana, Medellín, 2013). Disponible en: https://letrujil.files.wordpress. com/2013/09/43maria-patricia-balanta-m.pdf, http://letrujil.com/memorias/ xxxiv-congreso-colombiano-derecho-procesal/

Canosa-SuÁrez, Ulises, Código General del Proceso. Aspectos probatorios, en Memorias del XXXIII Congreso Colombiano de Derecho Procesal, Cartagena, 12, 13 y 14 de septiembre de 2012, 33-62 (Universidad Libre, Bogotá, 2012). Disponible en: https://letrujil.files.wordpress.com/2012/09/derechoprocesalfinal.pdf

Canosa-Suárez, Ulises, Presentación del CGP por el ICDP, en Código General del Proceso: Ley 1564 de 2012 (julio 12), Decreto 1736 de 2012, y notas de constitucionalidad. Comentado, con artículos explicativos de miembros del ICDP, 7-15 (Instituto Colombiano de Derecho Procesal, ICDP, Bogotá, 2014).

Colmenares-Uribe, Carlos A., El procedimiento monitorio en Colombia, en El procedimiento monitorio en América Latina. Pasado, presente y futuro, 109-175 ( $1^{a}$ ed., Jordi Nieva-Fenoll, Rodrigo Rivera-Morales, Juan Pablo CorreaDelcasso \& Carlos A. Colmenares-Uribe, Editorial Temis S.A., Bogotá, 2013).

Nieva-Fenoll, Jordi, El elemento psicológico en la adopción de las medidas cautelares, en Memorias del IX Congreso Internacional de Derecho Procesal, San José de Cúcuta, 2 y 3 de agosto de 2013, 107-128 (Universidad Libre Seccional Cúcuta, Cúcuta, 2013).

Parra-Quijano, Jairo, Crisis de la noción clásica de la carga de la prueba, en Memorias XVI Congreso Colombiano de Derecho Procesal, Cali, 6, 7 y 8 de septiembre de 1995, 16-26 (Instituto Colombiano de Derecho Procesal, ICDP, Universidad Libre, Cali, 1995). Disponible en: http://publicacionesicdp.com/index.php/ Revistas-icdp/article/view/219/pdf

Parra-Quijano, Jairo, Reflexiones sobre algunos aspectos importantes del Código General del Proceso, en Memorias del XXXIII Congreso Colombiano de Derecho Procesal, Cartagena, 12, 13 y 14 de septiembre de 2012, 17-32 (Universidad Libre, Bogotá, 2012). Disponible en: https://letrujil.files.wordpress.com/2012/09/ derechoprocesalfinal.pdf

Peyrano, Jorge W., La carga de la prueba, en Memorias del XXXIV Congreso Colombiano de Derecho Procesal, Medellín, 11, 12 y 13 de septiembre de 2013, 955-974 (Universidad Pontificia Bolivariana, Medellín, 2013). Disponible en: https:// letrujil.files.wordpress.com/2013/09/38jorge-w-peyrano.pdf

Ramírez-Carvajal, Diana María, Una mirada a la prueba en la reforma procesal civil, en Reformas procesales en Colombia y en el mundo, 617-633 (MónICA MARía Bustamante-Rúa, Universidad de Medellín, Medellín, 2014). 
Rivera-Morales, Rodrigo, Derecho constitucional de la prueba, en VIII Congreso Internacional de Derecho Procesal, 211-232 (1 ${ }^{\mathrm{a}}$ ed., Universidad Libre Seccional Cúcuta, Cúcuta, 2012).

Rojas-Ríos, Alberto, La carga dinámica de la prueba en la jurisprudencia de la Corte Constitucional, en Memorias del XXXIV Congreso Colombiano de Derecho Procesal, Medellín, 11, 12 y 13 de septiembre de 2013, 943-953 (Universidad Pontificia Bolivariana, Medellín, 2013). Disponible en: https://letrujil.files. wordpress.com/2013/09/37alberto-rojas-rios.pdf

\section{Revistas}

Pérez-Restrepo, Juliana, La carga dinámica de la prueba en la responsabilidad administrativa por la actividad médica — decaimiento de su aplicabilidad-, 68 Revista Estudios de Derecho, 152, 201-225 (julio-diciembre de 2011). Disponible en: http://www.leyex.info/magazines/vol68n1521.pdf

\section{Conferencias, discursos, ponencias}

Acero-Gallego, Luis Guillermo, La carga de la prueba. Régimen probatorio - Carga de la prueba (Universidad Externado de Colombia, Bogotá, 2 de agosto de 2014). Disponible en: https://www.youtube.com/watch?v=IeAcIguk2UY

Bejarano-Guzmán, Ramiro, Régimen probatorio (Universidad de Los Andes, Bogotá, 18 de febrero de 2013). Disponible en: https://www.youtube.com/watch?v=WzqsubT2YM

Santos-Calderón, Juan Manuel, Palabras del presidente Juan Manuel Santos en la sanción del Código General del Proceso y del Estatuto de Arbitraje Nacional e Internacional, y posesión de la Ministra de Justicia, Ruth Stella Correa-Palacio (Presidencia de la República, Bogotá, 12 de julio de 2012). Disponible en: http:// wsp.presidencia.gov.co/Prensa/2012/Julio/Paginas/20120712_11.aspx

\section{Normatividad colombiana}

Colombia, Acto Legislativo 03 de 2002, por el cual se reforma la Constitución Nacional, 45.040 Diario Oficial, 20 de diciembre de 2002. Disponible en: http://www. secretariasenado.gov.co/senado/basedoc/acto_legislativo_03_2002.html

Colombia, Constitución Política, 7 de julio de 1991. Versión corregida, 116 Gaceta Constitucional, 20 de julio de 1991, disponible en: http://www.secretariasenado. gov.co/senado/basedoc/constitucion_politica_1991.html

Colombia, Decreto 1400 de 1970, por el cual se expide el Código de Procedimiento Civil, CPC, 33.150 Diario Oficial, 21 de septiembre de 1970. Disponible en: http://www. alcaldiabogota.gov.co/sisjur/normas/Norma1.jsp?i=6923

Colombia, Ley 57 de 1887, por la cual se expide el Código Civil, CC. Disponible en: http://www.secretariasenado.gov.co/senado/basedoc/codigo_civil.html 
Colombia, Ley 906 de 2004, por la cual se expide el Código de Procedimiento Penal, CPP, 45.658 Diario Oficial, 1 de septiembre de 2004. Disponible en: http://www. secretariasenado.gov.co/senado/basedoc/ley_0906_2004.html

Colombia, Ley 1437 de 2011, por la cual se expide el Código de Procedimiento Administrativo y de lo Contencioso Administrativo, 47.956 Diario Oficial, 18 de enero de 2011. Disponible en: http://www.secretariasenado.gov.co/senado/ basedoc/ley_1437_2011.html

Colombia, Ley 1563 de 2012, por medio de la cual se expide el Estatuto de Arbitraje Nacional e Internacional y se dictan otras disposiciones, 48.489 Diario Oficial, 12 de julio de 2012. Disponible en: http://www.secretariasenado.gov.co/senado/ basedoc/ley_1563_2012.html

Colombia, Ley 1564 de 2012, por medio de la cual se expide el Código General del Proceso, CGP y se dictan otras disposiciones, 48.489 Diario Oficial, 12 de julio de 2012. Disponible en: http://www.secretariasenado.gov.co/senado/basedoc/ ley_1564_2012.html

\section{Jurisprudencia colombiana}

Consejo de Estado, Sala de lo Contencioso Administrativo, Sección Tercera, Sentencia 22355, 16 de mayo de 2002, Leydi Jazmín Rodríguez Rojas y otros vs. departamento del Casanare y otro, consejero ponente Ricardo Hoyos-Duque. Disponible en: http://www.notinet.com.co/pedidos/22355.htm

Corte Constitucional, Sala Plena, Auto A206-06, 1 de agosto de 2006, referencia: solicitud de nulidad de la sentencia T-1037 de 2005, expedientes T-1116870, T-1116878 y T-1137024, magistrado ponente Jaime Araújo-Rentería. Disponible en: http://www.corteconstitucional.gov.co/relatoria/autos/2006/A206-06.htm

Corte Constitucional, Sala Plena, Auto A227-07, 29 de agosto de 2007, referencia: solicitud de nulidad de la Sentencia T-233 de 2007, proferida por la Sala Quinta de Revisión de Tutelas de la Corte Constitucional, magistrado ponente Marco Gerardo Monroy-Cabra. Expediente T-1498919. Disponible en: http://www. corteconstitucional.gov.co/relatoria/autos/2007/a227-07.htm

Corte Constitucional, Sala Plena, Sentencia C-396-07, 23 de mayo de 2007, expediente D-6482, magistrado ponente Marco Gerardo Monroy-Cabra. Disponible en: http://www.corteconstitucional.gov.co/relatoria/2007/C-396-07.htm

Corte Constitucional, Sala Plena, Sentencia C-610-12, 1 de agosto de 2012, expediente D-8941, magistrado ponente Luis Ernesto Vargas-Silva. http://www. corteconstitucional.gov.co/relatoria/2012/c-610-12.htm

Corte Constitucional, Sala Cuarta de Revisión, Sentencia T-321-93, 10 de agosto de 1993, expediente T-14365, magistrado ponente Carlos Gaviria-Díaz. Disponible en: http://www.corteconstitucional.gov.co/relatoria/1993/t-321-93.htm

Corte Constitucional, Sala Primera de Revisión, Sentencia T-504-98, 10 de septiembre de 1998, expediente T-176879, magistrado ponente Alfredo Beltrán-Sierra. Disponible en: http://www.corteconstitucional.gov.co/relatoria/1998/t-504-98. htm 
Corte Constitucional, Sala Quinta de Revisión, Sentencia T-555-99, 2 de agosto de 1999, expediente T-197404, magistrado ponente José Gregorio Hernández-Galindo. Disponible en: http://www.corteconstitucional.gov.co/relatoria/1999/t-555-99.htm

Corte Constitucional, Sala Tercera de Revisión, Sentencia T-589-99, 13 de agosto de 1999, expediente T-210000, magistrado ponente Eduardo Cifuentes-Muñoz. Disponible en: http://www.corteconstitucional.gov.co/relatoria/1999/t-589-99.htm

Corte Constitucional, Sala Séptima de Revisión, Sentencia T-864-99, 3 de noviembre de 1999, expedientes T-213.553, T-224.704, T-226.889 y T-229.153 (acumulados), magistrado ponente Alejandro Martínez-Caballero. Disponible en: http://www. corteconstitucional.gov.co/relatoria/1999/t-864-99.htm

Corte Constitucional, Sala Sexta de Revisión, Sentencia T-498-00, 4 de mayo de 2000, expediente T-290.279, magistrado ponente Alejandro Martínez-Caballero. Disponible en: http://www.corteconstitucional.gov.co/relatoria/2000/t-498-00. htm

Corte Constitucional, Sala Quinta de Revisión, Sentencia T-1181-00, 7 de septiembre de 2000, expediente T-264130, magistrado ponente José Gregorio Hernández-Galindo. Disponible en: http://corteconstitucional.gov.co/ relatoria/2000/t-1181-00.htm

Corte Constitucional, Sala Quinta de Revisión, Sentencia T-1207-01, 16 de noviembre de 2001, expedientes T-483392, T-489367 y T-497997, magistrado ponente Rodrigo Escobar-Gil. Disponible en: http://corteconstitucional.gov.co/ relatoria/2001/t-1207-01.htm

Corte Constitucional, Sala Cuarta de Revisión, Sentencia T-696-02, 29 de agosto de 2002, expediente T-543775, magistrado ponente Jaime Córdoba-Triviño. Disponible en: http://www.corteconstitucional.gov.co/relatoria/2002/t-696-02.htm

Corte Constitucional, Sala Segunda de Revisión, Sentencia T-699-02, 29 de agosto de 2002, expediente T-587.248, magistrado ponente Alfredo Beltrán-Sierra. Disponible en: http://www.corteconstitucional.gov.co/relatoria/2002/t-699-02. htm

Corte Constitucional, Sala Sexta de Revisión, Sentencia T-819-03, 18 de septiembre de 2003, expediente T-752 205, magistrado ponente Marco Gerardo Monroy-Cabra. Disponible en: http://www.corteconstitucional.gov.co/relatoria/2003/t-819-03. $\mathrm{htm}$

Corte Constitucional, Sala Sexta de Revisión, Sentencia T-653-04, 8 de julio de 2004, expediente T-856266, magistrado ponente Marco Gerardo Monroy-Cabra. Disponible en: http://www.corteconstitucional.gov.co/relatoria/2004/t-653-04. htm

Corte Constitucional, Sala Séptima de Revisión, Sentencia T-1276-05, 6 de diciembre de 2005, expediente T-1166403, magistrado ponente Humberto Antonio SierraPorto. Disponible en: http://corteconstitucional.gov.co/relatoria/2005/t-1276-05. htm

Corte Constitucional, Sala Octava de Revisión, Sentencia T-171-06, 7 de marzo de 2006, expediente T-1226076, magistrada ponente Clara Inés Vargas-Hernández. Disponible en: http://www.corteconstitucional.gov.co/relatoria/2006/t-171-06. htm 
Corte Constitucional, Sala Séptima de Revisión, Sentencia T-131-07, 22 de febrero de 2007, expediente T-1461325, magistrado ponente Humberto Antonio Sierra-Porto. Disponible en: http://www.corteconstitucional.gov.co/relatoria/2007/t-131-07.htm

Corte Constitucional, Sala Novena de Revisión, Sentencia T-474-08, 15 de mayo de 2008, expediente T-1773173, magistrada ponente Clara Inés Vargas-Hernández. Disponible en: http://www.corteconstitucional.gov.co/relatoria/2008/t-474-08. htm

Corte Constitucional, Sala Novena de Revisión, Sentencia T-077-09, 12 de febrero de 2009, expediente T-1842367, magistrada ponente Clara Inés Vargas-Hernández. Disponible en: http://corteconstitucional.gov.co/relatoria/2009/t-077-09.htm

Corte Constitucional, Sala Tercera de Revisión, Sentencia T-264-09, 3 de abril de 2009, expediente T-2.112.744, magistrado ponente Luis Ernesto Vargas-Silva. Disponible en: http://www.corteconstitucional.gov.co/relatoria/2009/t-264-09. htm

Corte Constitucional, Sala Sexta de Revisión, Sentencia T-510-09, 30 de julio de 2009, expediente T-2.137.392, magistrado ponente Jorge Ignacio Pretelt-Chaljub. Disponible en: http://www.corteconstitucional.gov.co/relatoria/2009/t-510-09. htm

Corte Constitucional, Sala Primera de Revisión, Sentencia T-600-09, 28 de agosto de 2009, expedientes T-2.203.830 T-2.206.643, T-2.214.482, T-2.300.579 y T-2.300.580 (acumulados), magistrado ponente Juan Carlos Henao-Pérez. Disponible en: http://www.corteconstitucional.gov.co/relatoria/2009/t-600-09.htm

Corte Constitucional, Sala Segunda de Revisión, Sentencia T-654-09, 17 de septiembre de 2009, expediente T-2271638, magistrada ponente María Victoria Calle-Correa. Disponible en: http://www.corteconstitucional.gov.co/relatoria/2009/t-654-09. htm

Corte Constitucional, Sala Tercera de Revisión, Sentencia T-211-10, 23 de marzo de 2010, expedientes T-2429160 y T-2447275, magistrado ponente Juan Carlos Henao-Pérez. Disponible en: http://www.corteconstitucional.gov.co/ relatoria/2010/t-211-10.htm

Corte Constitucional, Sala Primera de Revisión, Sentencia T-1013-10, 7 de diciembre de 2010, expediente T-2409781, magistrada ponente María Victoria Calle-Correa. Disponible en: http://corteconstitucional.gov.co/relatoria/2010/t-1013-10.htm

Corte Constitucional, Sala Tercera de Revisión, Sentencia T-141-11, 4 de marzo de 2011, expediente T-2.815.412, magistrado ponente Juan Carlos Henao-Pérez. Disponible en: http://www.corteconstitucional.gov.co/relatoria/2011/t-141-11.htm

Corte Constitucional, Sala Quinta de Revisión, Sentencia T-318-11, 4 de mayo de 2011, expediente T-2772734, magistrado ponente Jorge Iván Palacio-Palacio. Disponible en: http://www.corteconstitucional.gov.co/relatoria/2011/t-318-11.htm

Corte Constitucional, Sala Novena de Revisión, Sentencia T-638-11, 25 de agosto de 2011, expediente T-3008463, magistrado ponente Luis Ernesto Vargas-Silva. Disponible en: http://www.corteconstitucional.gov.co/relatoria/2011/t-638-11.htm

Corte Constitucional, Sala Primera de Revisión, Sentencia T-764-11, 7 de octubre de 2011, expediente T-3094889, magistrada ponente María Victoria Calle-Correa. Disponible en: http://www.corteconstitucional.gov.co/relatoria/2011/t-764-11.htm 
Corte Constitucional, Sala Quinta de Revisión, Sentencia T-950-11, 15 de diciembre de 2011, expediente T-3.200.240, magistrado ponente Jorge Iván Palacio-Palacio. Disponible en: http://www.corteconstitucional.gov.co/relatoria/2011/t-950-11.htm

Corte Constitucional, Sala Séptima de Revisión, Sentencia T-129-12, 7 de febrero de 2012, expediente T-3.256.073, magistrado ponente Jorge Ignacio Pretelt-Chaljub. Disponible en: http://www.corteconstitucional.gov.co/relatoria/2012/T-129-12. htm

Corte Constitucional, Sala Novena de Revisión, Sentencia T-213-12, 16 de marzo de 2012, expediente T-3206395, magistrado ponente Luis Ernesto Vargas-Silva. Disponible en: http://www.corteconstitucional.gov.co/relatoria/2012/t-213-12.htm

Corte Constitucional, Sala Octava de Revisión, Sentencia T-441-12, 14 de junio de 2012, expediente T-3.302.323, magistrado ponente Humberto Antonio Sierra-Porto. Disponible en: http://www.corteconstitucional.gov.co/relatoria/2012/t-441-12. htm

Corte Constitucional, Sala Novena de Revisión, Sentencia T-817-12, 16 de octubre de 2012, expediente T-3519074, magistrado ponente Luis Ernesto Vargas-Silva. Disponible en: http://www.corteconstitucional.gov.co/relatoria/2012/t-817-12.htm

Corte Constitucional, Sala Octava de Revisión, Sentencia T-076-13, 14 de febrero de 2013, expediente T-3417272, magistrado ponente Alexei Egor Julio-Estrada. Disponible en: http://www.corteconstitucional.gov.co/relatoria/2013/t-076-13.htm

Corte Constitucional, Sala Primera de Revisión, Sentencia T-429-13, 10 de julio de 2013, expediente T-3269699, magistrada ponente María Victoria Calle-Correa. Disponible en: http://www.corteconstitucional.gov.co/relatoria/2013/t-429-13.htm

Corte Constitucional, Sala Novena de Revisión, Sentencia T-775-14, 16 de octubre de 2014, expediente T-4017904, magistrado ponente Luis Ernesto Vargas-Silva. Disponible en: http://www.corteconstitucional.gov.co/relatoria/2014/t-775-14.htm

Corte Constitucional, Sala Plena, Sentencia SU-768-14, 16 de octubre de 2014, expediente T-3.955.581, magistrado ponente Jorge Iván Palacio-Palacio. Disponible en: http:// www.corteconstitucional.gov.co/relatoria/2014/SU768-14.htm

Corte Suprema de Justicia, Sala de Casación Penal, Sentencia 24468, 30 de marzo de 2006, magistrado ponente Édgar Lombana-Trujillo. Disponible en: http://www.cispa.gov.co/index.php?option $=$ com_docman\&task $=$ doc_ download\&gid $=551 \&$ Itemid $=24$ 
